\title{
Climate Change Downscaling Using Stochastic Weather Generator Model in Rift Valley Basins of Ethiopia
}

\author{
Kinde Negessa Disasa ${ }^{*}$, Feyisa Seboka Tura², Magarsa Ensarmu Fereda ${ }^{3}$ \\ ${ }^{1}$ Department of Water Resources and Irrigation Management, Ambo University, Ambo, Ethiopia \\ ${ }^{2}$ Department of Natural Resources Management, Ambo University, Ambo, Ethiopia \\ ${ }^{3}$ Department of Research and Development Directorate, Ministry of Water, Addis Abeba, Ethiopia \\ Email: *nagkindee@gmail.com
}

How to cite this paper: Disasa, K.N., Tura, F.S. and Fereda, M.E. (2019) Climate Change Downscaling Using Stochastic Weather Generator Model in Rift Valley Basins of Ethiopia. American Journal of Climate Change, 8, 561-590.

https://doi.org/10.4236/ajcc.2019.84030

Received: August 8, 2019

Accepted: December 16, 2019

Published: December 19, 2019

Copyright $\odot 2019$ by author(s) and Scientific Research Publishing Inc. This work is licensed under the Creative Commons Attribution International License (CC BY 4.0).

http://creativecommons.org/licenses/by/4.0/

\section{(c) (i) Open Access}

\begin{abstract}
Agriculture is the mainstay of Ethiopian economy. Developing country like Ethiopia suffers from climate change, due to their limited economic capability to build irrigation projects to combat the trouble. This study generates climate change in rift valley basins of Ethiopia for three time periods (2020s, 2055s and 2090s) by using two emission scenarios: SRA1B and SRB1 for faster technological and environmental extreme respectively. First, outputs of 15 General Circulation Models (GCMs) under two emission scenarios (SRA1B and SRB1) are statistically downscaled by using LARS-WG software. Probability assessment of bounded range with known distributions is used to deal with the uncertainties of GCMs' outputs. These GCMs outputs are weighted by considering the ability of each model to simulate historical records. The study result indicates that LARS-WG 5.5 version model is more uncertain to simulate future mean rainfall than generating maximum and minimum mean temperatures. GCMs weight difference for mean rainfall is 0.83 whereas weight difference for minimum and maximum mean temperatures is 0.09 among GCMs models. The study results indicate minimum and maximum temperatures absolute increase in the range of $0.34^{\circ} \mathrm{C}$ to $0.58^{\circ} \mathrm{C}, 0.94^{\circ} \mathrm{C}$ to $1.8^{\circ} \mathrm{C}$ and $1.42^{\circ} \mathrm{C}$ to $3.2^{\circ} \mathrm{C}$ and $0.32^{\circ} \mathrm{C}$ to $0.56^{\circ} \mathrm{C}, 0.91^{\circ} \mathrm{C}$ to $1.8^{\circ} \mathrm{C}$ and $1.34^{\circ} \mathrm{C}$ to $3.04^{\circ} \mathrm{C}$ respectively in the near-term (2020s), mid-term (2055s) and long-term (2090s) under both emission scenarios. The expected rainfall change percentage during these three time periods considering this GCMs weight difference into account ranges from $-2.3 \%$ to $7 \%, 0.375 \%$ to $15.83 \%$ and $2.625 \%$ to $31.1 \%$ in the same three time periods. In conclusion, the study results indicate that in coming three time periods, maximum and minimum temperature and rainfall increase is expected in rift valley of basins of Ethiopia.
\end{abstract}




\section{Keywords}

Climate Change, IPCC AR4, LARS-WG Statistical Downscaling, 15 GCM

Ensembles

\section{Introduction}

Climate change is considered to be the biggest challenge facing by mankind in the twenty first century. The change in the climate mean state within a certain time period is referred to as climate variability which can be more detrimental than climate change. Both climate variability and change can lead to severe impacts on different major sectors of the world such as water resources, agriculture, energy and tourism [1]. In the United States and other developed nations, extensive studies on the impacts of climate change on agricultural production have been carried out [2]. There has been relatively little research in developing nations although recently, a few papers have been published [3], [4]. Yet, developing countries like Ethiopia are the ones which could suffer more from the effects of climate change, due to their limited economic capability for constructing irrigation projects to abbreviate climate change impact on crop production which is dominantly based on rainfall. Research conducted on climate change and Ethiopian economy explained that agriculture in Ethiopia is heavily dependent on rain. In addition to its low adaptive capacity, its geographical location and topography make the country highly vulnerable to the adverse impacts of climate change. Results indicate that, over a 50-year period, the projected reduction in agricultural productivity may lead to 30 percent less average income, compared with the possible outcome in the absence of climate change [5].

Extreme events are common in Ethiopia, especially droughts. According to an analysis in 2011, Ethiopia was ranked 5th out of 184 countries in terms of its risk of drought [6]. Between 1900 and 2010, twelve extreme droughts were recorded (killing over 400,000 people and affecting over 54 million) [7], of which seven occurred since 1980 and the majority of these resulted in famines [8]. The severe drought of 2015-2016 was exacerbated by the strongest El Nino in decades, caused successive harvest failures and widespread livestock deaths in some regions. Apart from these major or extreme droughts, there have been dozens of local droughts with equally devastating effects. The country has experienced even more major floods in different parts of the country, though with fewer people affected: 47 major floods since 1900 (of which six since 1980) [8] killed almost 2000 people and affected 2.2 million [7].

General Circulation Models (GCMs) are "computer based version of earth's system that mathematically simulates the climate system and the interaction between the system components" [9]. They simulate historical, present and future climate scenarios taking into account the level of greenhouse gases and aerosols under different future projections. The process is achieved by dividing 
the oceans and atmosphere into a horizontal grid with a horizontal resolution of 20 - 480 with 10 - 20 layers aligned vertically. This enables predictions of climate change for the next 100 years using a coarse grid scale [10]. In general, most GCMs are capable of simulating global and continental scale processes in detail and provide a reliable representation of the average planetary climate [9]. Global climate models "are the only credible tools currently available for simulating the response of the global climate system to increasing greenhouse gas (GHG) concentrations" [1]. GCMs are fully coupled mathematical representations of the complex physical laws and interactions between ocean/atmosphere/sea-ice/ land-surface [11]. They simulate the behavior of the climate system on a variety of temporal and spatial scales using a three-dimensional grid over the globe. GCM experiments simulate future climate conditions based on estimated warming effects of carbon dioxide (CO2) and other GHGs and the regional cooling effects of increasing sulphate aerosols, beginning in the late 19th century or early 20th century using scenarios of future radiative forcing. Ethiopia is one of the world's lowest emitters of GHG emissions, ranking 182 of 188 countries on per capita emissions [12] and contributing $0.27 \%$ of global emissions [13]. However, Ethiopia is highly vulnerable to global climate change.

The Intergovernmental Panel on Climate Change Third Assessment Report [14] published forty different emission scenarios provide a range of future possible GHG emissions and atmospheric concentrations from socio-economic scenarios labeled SRES (Special Report on Emission Scenarios) [15]. The SRES describes 4 narrative storylines (i.e. A1, A2, B1 and B2) which represent different demographic, social, economic, technological, and environmental and policy future, as emission drivers. The SRES emissions scenarios are the quantitative interpretations of these qualitative storylines. Typically of interest are the pre-industrial control experiments, which run for long periods holding the forcing agents at fixed levels of the year 1850. They are used to assess the GCMs ability to reproduce historical natural climate variability and also provide reference for the 20th Century and SRES experiments. The 20th Century experiment begins in the middle of the 19th century continuing to the end of the 21st century with the forcing agents representing the historical record.

The main objective of this study is to generate future changes in maximum and minimum temperature and rainfall at three time periods (2020s, 2055s and 2090s) in rift valley basins of Ethiopia. Two commonly used emission scenarios SRA1B and SRB1, are considered here in the analysis of the future climate change in rift valley basins of Ethiopia which is characterized by very rapid economic growth $(3 \% / y r)$, low population growth $(0.27 \% / y r)$ and rapid introduction of new and more efficient technology. Globally there is economic and cultural convergence and capacity building, with a substantial reduction in regional differences in per capita income for the first scenario and rapid change in economic structures, "dematerialization" including improved equity and environmental concern. There is a global concern regarding environmental and social sustainability and more effort in introducing clean technologies. The global 
population reaches 7 billion by twenty first century for second scenario respectively [1].

\section{Materials and Method}

\subsection{Study Area}

This study was conducted in Hawassa zuria district which surrounds Hawassa town the capital of SNNPR that constitutes different land forms, which can be broadly divided into highlands and low lands. The East African Rift valley bisects the highland plateaus in to two physiographic regions i.e. east and west. In the east, there are highland plateaus of Sidama, Burji and Amaro lying between 2300 to 3338 meters above sea level (masl). The study site is located in east of the rift valley in sidama zone (Figure 1). Hawassa zuria district is located in the Great Rift Valley of Ethiopia and at $273 \mathrm{~km}$ distance from Addis Abeba capital city of Ethiopia. It covers latitudinal area from $6.95^{\circ} \mathrm{N}$ to $7.13^{\circ} \mathrm{N}$ and longitudinal area $38.5^{\circ} \mathrm{E}$ to $38.73^{\circ} \mathrm{E}$. Hawassa zuria has an annual average rainfall of 955 $\mathrm{mm}$ with mean annual temperature of $20^{\circ} \mathrm{C}$ [16]. The main rainy season generally extends from June to October.

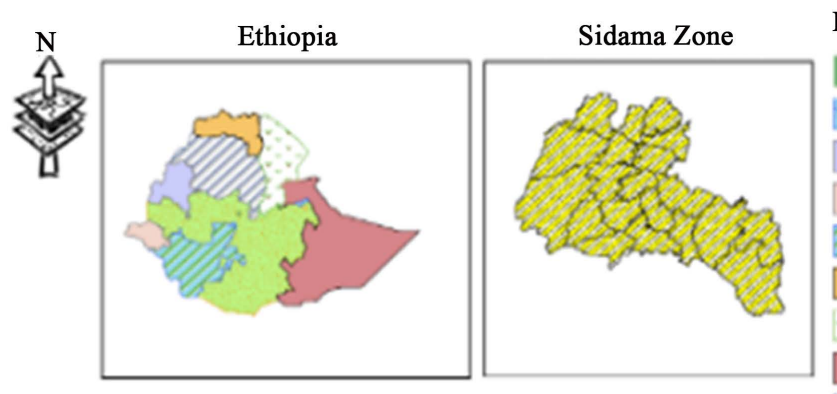

Hawassa Zuria Woreda (study Area)

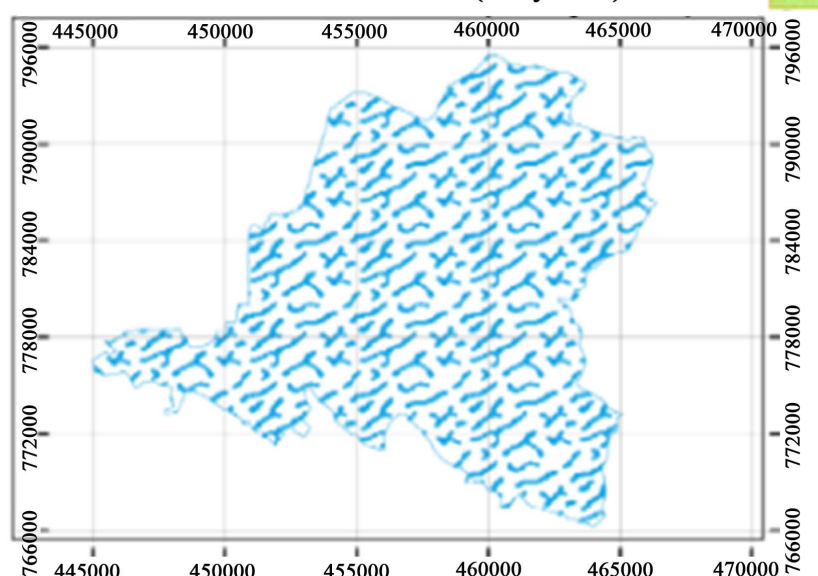

Coordinate System: Adindan UTM Zone 37N Projection: Transverse Mercator Datum: Adindan False Easting: 500,000.0000 False Northing: 0.0000 Central Meridian: 30,0000 Latitude Of Orgin: 0.0000 Units Meter

$1: 250,000$

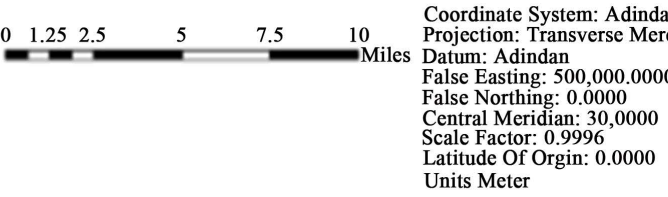

Legend

Addis_Ababa_Adm Dire_dewa_adm Ben Gumuz Region Gambella Region Southern Region Tigry Region Afar Region Somale Region Amhara Region Oromia Region

Figure 1. Map of the study area. 


\subsection{Baseline Period Data Selection}

The baseline period is the reference period on which calculation of future climate changes is based. Definition of the baseline period is important in order to select the observed climate dataset that combines with climate change information to generate climate change projections [17]. [9], [18] and [19] outline four criteria that are commonly used in selection of the baseline period.

1) The baseline period must truly represent the current or recent averages of climate conditions within the area.

2) The baseline period must be sufficiently long and cover a wide range of climate variations, including extreme weather conditions.

3) The suitable baseline period is the one for which the major climatic data like rainfall (precipitation), temperature, sunshine and relative humidity are readily available, easily accessible and adequately distributed over space.

4) The baseline period should have high quality climate data (with few missing data, if any).

Based on these four selection criteria mentioned a baseline period of 30 years meteorological data from (1985-2014) was used to generate synthetic weather data.

\subsection{Description of Long Ashton Research Department Station Weather Generator (LARS-WG)}

Long Ashton Research Station Weather Generator (LARS-WG Version 5.5, to date version) was used for this study to simulate future weather data for Ethiopia and the model used data of southern region of Ethiopia specifically Hawassa zuria district as a case study. LARS-WG is implemented in $\mathrm{C}++$ with full Windows interface and is freely accessible at

http://www.rothamsted.ac.uk/mas-models/larswg.php (by providing LARS-WG specific site derivatives e.g. site parameter and diagnostics files, with the research community). The model simulates weather data at a single site under current and future conditions [20]. LARS-WG Version 5.5 also includes fifteen (15) General Climate Models (GCMs) which have been used in the IPCC 4th Assessment Report (2007). The simulated data from the model are in form of daily time-series for the following climate variables [21].

Maximum and minimum temperature $\left({ }^{\circ} \mathrm{C}\right)$, precipitation $(\mathrm{mm})$ and solar radiation in Mega joule per square meter per day $\left(\mathrm{MJ} / \mathrm{m}^{2} /\right.$ day $)$

Table 1 presents General Climate Models (GCMs) incorporated in LARS WG 5.5 with their respective grid resolution, emission scenarios and time periods based on baseline.

\subsection{Model Calibration and Validation}

The process of generating synthetic weather data can be grouped into three distinct steps [21]: 1) model calibration, 2) model validation and 3) generation of synthetic weather data analysis. 
Table 1. Global climate models from IPCC AR4 incorporated into the LARS-WG stochastic weather generator version 5.5 used in this study. B: baseline; T1: 2011-2030; T2: 2046-2065; T3: 2080-2099 [22].

\begin{tabular}{|c|c|c|c|c|c|c|}
\hline Research Centre & Country & $\begin{array}{c}\text { Global } \\
\text { Climate Model }\end{array}$ & $\begin{array}{c}\text { Model } \\
\text { Acronym }\end{array}$ & $\begin{array}{c}\text { Grid } \\
\text { Resolution }\end{array}$ & $\begin{array}{l}\text { Emission } \\
\text { Scenarios }\end{array}$ & $\begin{array}{l}\text { Time } \\
\text { Periods }\end{array}$ \\
\hline $\begin{array}{l}\text { Commonwealth Scientific and } \\
\text { Industrial Research Organization }\end{array}$ & Australia & CSIRO-MK3.0 & CSMK3 & & SRA1B, SRB1 & $\mathrm{B}, \mathrm{T} 1, \mathrm{~T} 2, \mathrm{~T} 3$ \\
\hline $\begin{array}{l}\text { Canadian Centre for Climate } \\
\text { Modelling and Analysis }\end{array}$ & Canada & CGCM33.1 (T47) & CGMR & $2.8 \times 2.8^{\circ}$ & SRA1B & $\mathrm{B}, \mathrm{T} 1, \mathrm{~T} 2, \mathrm{~T} 3$ \\
\hline Institute of Atmospheric Physics & China & FGOALS-g1.0 & FGOALS & $2.8 \times 2.8^{\circ}$ & SRA1B, SRB1 & $\mathrm{B}, \mathrm{T} 1, \mathrm{~T} 2, \mathrm{~T} 3$ \\
\hline Centre National de Recherches Meteorologiques & France & CNRM-CM3 & CNCM3 & $1.9 \times 1.9^{\circ}$ & SRA1B, SRA2 & $\mathrm{B}, \mathrm{T} 1, \mathrm{~T} 2, \mathrm{~T} 3$ \\
\hline Institute Pierre Simon Laplace & France & PSL-CM4 & IPCM4 & $2.5 \times 3.75^{\circ}$ & SRA1B, SRA2, SRB1 & $\mathrm{B}, \mathrm{T} 1, \mathrm{~T} 2, \mathrm{~T} 3$ \\
\hline Max-Planck Institute for Meteorology & Germany & ECHAM5-OM & MPEH5 & $1.9 \times 1.9^{\circ}$ & SRA1B, SRA2, SRB1 & $\mathrm{B}, \mathrm{T} 1, \mathrm{~T} 2, \mathrm{~T} 3$ \\
\hline National Institute for Environmental Studies & Japan & MRI-CGCM2.3.2 & MIHR & $2.8 \times 2.8^{\circ}$ & SRA1B, SRB1 & $\mathrm{B}, \mathrm{T} 1, \mathrm{~T} 2, \mathrm{~T} 3$ \\
\hline Bjerknes Centre for Climate Research & Norway & BCM2.0 & BCM2 & $1.9 \times 1.9^{\circ}$ & SRA1B, SRB1 & $\mathrm{B}, \mathrm{T} 1, \mathrm{~T} 2, \mathrm{~T} 3$ \\
\hline Institute for Numerical Mathematics & Russia & INM-CM3.0 & INCM3 & $4 \times 5^{\circ}$ & SRA1B, SRA2, SRB1 & $\mathrm{B}, \mathrm{T} 1, \mathrm{~T} 2, \mathrm{~T} 3$ \\
\hline \multirow{2}{*}{ UK Meteorological Office } & \multirow{2}{*}{ UK } & HadCM3 & HADCM3 & $2.5 \times 3.75^{\circ}$ & SRA1B, SRA2, SRB1 & $\mathrm{B}, \mathrm{T} 1, \mathrm{~T} 2, \mathrm{~T} 3$ \\
\hline & & HadGEM1 & HADGEM & $1.3 \times 1.9^{\circ}$ & SRA1B, SRA2 & $\mathrm{B}, \mathrm{T} 1, \mathrm{~T} 2$ \\
\hline Geophysical Fluid Dynamics Lab & USA & GFDL-CM2.1 & GFCM21 & $2.0 \times 2.5^{\circ}$ & SRA1B, SRA2, SRB1 & $\mathrm{B}, \mathrm{T} 1, \mathrm{~T} 2, \mathrm{~T} 3$ \\
\hline Goddard Institute for Space Studies & USA & GISS-AOM & GIAOM & $3 \times 4^{\circ}$ & SRA1B, SRB1 & $\mathrm{B}, \mathrm{T} 1, \mathrm{~T} 2, \mathrm{~T} 3$ \\
\hline \multirow{2}{*}{ National Centre for Atmospheric Research } & USA & PCM & NCPCM & $2.8 \times 2.8^{\circ}$ & SRA1B, SRB1 & $\mathrm{B}, \mathrm{T} 1, \mathrm{~T} 2$, \\
\hline & USA & CCSM3 & NCCCS & $1.4 \times 1.4^{\circ}$ & SRA1B, SRA2, SRB1 & $\mathrm{B}, \mathrm{T} 1, \mathrm{~T} 2, \mathrm{~T} 3$ \\
\hline
\end{tabular}

\subsubsection{Calibration of the Model}

Calibration is the first step that is executed by the model in order to generate synthetic weather data. Calibration of LARS-WG is carried out by a function on the main menu called "Site Analysis". The process is done so as to determine statistical characteristics and site parameters of the observed weather data. In this study, site analysis was performed on observed data for a period of 30 years (1985-2014). Once the program encounters "illegal data" during execution, an "error" is displayed. "Illegal" data includes the value of minimum temperature being greater than maximum temperature and being precipitation values less than zero (negative precipitation) [21].

During calibration period the model calculates the mean and standard deviation for generated and observed data based on 30 years input data and $t, \mathrm{~K}-\mathrm{S}$ and f-statistics with their respective p-value for the three climate variables (rainfall, maximum and minimum temperature).

\subsubsection{Model Validation}

Once LARS-WG has been calibrated, its ability to simulate future weather data in the representative study site is assessed. Validation is a process that is used to determine how well a model can simulate potential future climate variables. The process involves comparing and analyzing the statistical characteristics of the observed and synthetic weather data in order to determine the existence of any 
statistically-significant differences between them. Validation of the model can be conducted in two different ways: 1) using the GENERATOR option to synthesize daily weather data based on the information in the site parameter files and then undertake comparisons between the observed and synthetic data "off-line", or 2) using the Q-test option that executes statistical comparisons between climate parameters derived from observed weather data and synthetic weather data generated using LARS-WG. The Q test function was used to determine the ability of LARS-WG to rationally estimate future climate variables. This was achieved using three statistical tests; chi-square test $\left(\mathrm{X}^{2}\right)$, t-test and $\mathrm{K}-\mathrm{S}$ (Kolmogorov-Smirnov) which is output $Q$ test function to test the performance of LARS-WG. The chi-square test was used to determine the existence of any significant difference between the simulated and observed frequencies in the meteorological data. A t-test was used to check the existence of any reliable difference between the means of the generated and observed data sets. Additionally; a K-S test was used to decide if a sample comes from population with a specific distribution. The Kolmogorov-Smirnov (K-S) statistic $\Delta$ is the absolute maximum differences between observed cumulative probability $P\left(X_{m}\right)$ and the theoretical cumulative probability $F\left(X_{m}\right)$.

$$
\Delta=\max \left|F\left(X_{m}\right)-P\left(X_{m}\right)\right|
$$

Observed cumulative probability is computed using Weibul's formula $P\left(X_{m}\right)=\left|\frac{n+1-m}{n+1}\right|$ and theoretical cumulative probability is obtained for each ordered observation using the selected distribution.

Where $\mathrm{n}$ is sample size and $\mathrm{m}$ is ordered sequence or rank.

By using two statistical tests $X^{2}$ (chi-square) and t-test we calibrate and validate LARS-WG model. In addition to these two tests $K-S$ test is used to cross check whether observed and generated distribution is from the same population or not. Large $X^{2}$ and $t$ values indicate the existence of real difference between observed and estimated/generated climate variables. Conversely, smaller $X^{2}$ and $t$ values indicate that there is less difference between observed and estimated data sets. $K-S$ value also should be less than critical value to accept the null hypothesis $\mathrm{H}_{\mathrm{o}}$ that says the generated data distribution has the same population distribution as observed data sets. Each $X^{2}, t$ and $K-S$ value has a corresponding $p$-value output from the model Q-test button, which is the probability that the pattern of data in the sample could be produced by random variables. A p-value of 0.05 simply means there is a probability of $5 \%$ that there is no difference between observed and simulated data. $P$-values below the set significance level indicate that the simulated climate variables are far from the true climate values. For the purpose of this study, a $p$-value was set at 0.05 which is commonly used in statistical tests and climate change studies [23].

\subsubsection{Generation of Synthetic Weather Data}

Once LARS-WG has been calibrated (Site Analysis) and the performance of the 
weather generator has been verified (Q-test), the "Generator" option then generates synthetic weather data. Synthetic weather data generated from this option have the same characteristics as observed weather data. This option also enables one to generate synthetic weather data analogous to a scenario of climate change. The following output data is obtained from this function:

Relative change in monthly mean rainfall

Relative change in duration of wet and dry spell

Absolute change in monthly mean minimum temperature

Absolute change in monthly mean maximum temperature

$>$ Relative changes in daily temperature variability

Absolute change in monthly mean radiation

LARS-WG is based on the series weather generator described in [19]. It utilizes semi-empirical distributions (SED) for the lengths of wet and dry day series, daily precipitation, minimum and maximum temperature and daily solar radiation. The semi-empirical distribution $\operatorname{Emp}=\left\{a_{0}, a_{i} ; h_{i}, i=1, \cdots, 23\right\}$, is a histogram with 23 intervals, $\left(a_{i-1}, a_{i}\right)$, where $a_{i-1}<a_{i}$ and $h_{i}$ denotes the number of events from the observed data in the ith interval. Random values from the semi-empirical distributions are chosen by first selecting one of the intervals (using the proportion of events in each interval as the selection probability), and then selecting a value within that interval from the uniform distribution. Such a distribution is flexible and can approximate a wide variety of shapes by adjusting the intervals $\left[a_{i-1}, a_{i}\right)$. The cost of this flexibility, however, is that the distribution requires many parameters (24 parameters for the edges and 23 parameters for the number of events in each interval) to be specified compared with, for example, 3 parameters for the mixed-exponential distribution used in an earlier version of the model to define the dry and wet day series [24].

\subsection{Uncertainty Analysis of GCMs}

\subsubsection{Weighting of GCMs}

The first step of this technique involves weighting each of the 15 GCMs used in the study based on the Mean Observed Temperature-Precipitation (MOTP) method [25]; [23]. In order to weight each GCM, the ability of the model to project weather data is considered. In other words, the method considers the monthly average difference between observed and simulated climate variables (precipitation and minimum and maximum temperature).

$$
w_{i j}=\frac{\frac{1}{\left|\Delta d_{i j}\right|}}{\sum_{j=1}^{15}\left[\frac{1}{\left|\Delta d_{i j}\right|}\right]}
$$

where $w_{i j}$ is the weight of GCM $j$ in month $i$; and $\left|\Delta d_{i j}\right|$ is the absolute difference between the average precipitation (rainfall) or temperature between observed value and the value simulated by GCM $j$ in month $i$. 


\subsubsection{Generation of Probability Distribution Functions (PDFs)}

This step implies generation of PDFs of changes in climate variables based on the calculated weights. The PDFs outline the relationship between the weight of each GCM and the average changes in monthly precipitation, minimum temperature and maximum temperature. With 15 GCMs and 2 emission scenarios used in this work, 30 PDFs are thus constructed for each month. The generated discrete PDFs of the main variables are ultimately converted to cumulative probability functions (CDFs). Several studies have identified the use of Gamma distribution function as an important tool for analysis of climate data [23]; [26]; [27]; [28]. Based on similar studies that were carried by [29], [30] and [23], the Gamma function has been selected for generation of cumulative distribution functions as follows;

$$
f(x)=\frac{1}{\beta^{\alpha} \Gamma(\alpha)} X^{\alpha-1} \mathrm{e}^{-x / \beta} ; x \geq 0
$$

where $\alpha$ and $\beta$ are shape and scale parameters of the Gamma distribution function respectively, $-x$ is the climate variable (temperature or precipitation), and is the incomplete Gamma function as given in Equation below.

$$
\Gamma(\alpha)=\int_{0}^{\infty} x^{\alpha-1} \mathrm{e}^{-x} \mathrm{~d} x
$$

By changing values of $\alpha$ and $\beta$, we obtain the best fit based on maximum likelihood model. The summation of squared error (Equation (19)) has been used to show how best the Gamma function fits the data.

$$
\operatorname{SSE}=\sum_{i=1}^{n}\left(y_{i}-\bar{y}_{i}\right)
$$

where $y_{i}$ is the data point; $\bar{y}_{i}$ is the estimation of Gamma function and $n$ is the number of data points. For this study, $n=15$.

\subsubsection{Generation of Cumulative Distribution Functions (CDFs)}

In this step, the PDFs generated in the second step are converted to CDFs for each of the 12 months (January-December). Next, values of climate change variables at three probability percentiles are extracted from the generated CDFs at the following risk levels: $25^{\text {th }}, 50^{\text {th }}$, and $75^{\text {th }}$ probability percentiles. The 25 th probability percentile indicates a scenario of high changes in precipitation and low temperature changes. The 75th probability percentile represents a scenario with low changes in precipitation but high temperature changes. The 50th probability percentile is the median probability percentile for both precipitation and temperature. The generated PDFs were converted to CDFs using the gamma distribution function whose shape and scale parameters alpha $(\alpha)$ and beta $(\beta)$ were as coded in MATLAB programming language which was resulted in high strength correlation coefficient $(r=0.999)$.

\section{Result and Discussion}

\subsection{Calibration and Validation of LARS-WG}

The output from Q-test of the model is used for calibration and validation of the 
software [21]. The $\chi^{2}, \mathrm{t}$ - and $\mathrm{p}$-tests assume that the observed weather is a random sample from some existing distribution, which represents the 'true' climate at the site. In the absence of any changes in climate, this true distribution could be estimated accurately from observed data over a very long time period. Figure 2 presents the monthly $\mathrm{p}$-values of $\mathrm{X}^{2}, \mathrm{~K}-\mathrm{S}$ and $\mathrm{t}$-tests for rainfall; $\mathrm{K}-\mathrm{S}$ and $\mathrm{t}$-tests plot for minimum and maximum temperatures based on [21]. The figure indicates p-value for chi-square and t-test varies among months whereas p-value for $\mathrm{k}-\mathrm{S}$ test approaches to unity for all months which shows generated and observed climate variables are from the same population [23]. The results indicate that $\mathrm{p}$-values in all months for both rainfall and temperatures are higher than the selected significance level of 0.05 for the three tests. Thus the model is satisfactorily to simulate future climate data.

Indeed Figure 3 shows that the mean and standard deviation of monthly observed data resemble with generated data for three climate variables rainfall, maximum and minimum temperatures. This ensures our confidence to use LARSWG5.5 for future synthetic meteorological weather data generation.

\subsection{Future Climate Variables Generation}

Future mean climate variables (rainfall and temperatures) for fifteen (15) GCMs are generated using Generator key function of LARS-WG 5.5 with perspective to two emission scenario (SRA1B and SRB1) in the model. Figures 4-6 show the simulated mean monthly values of rainfall, minimum and maximum
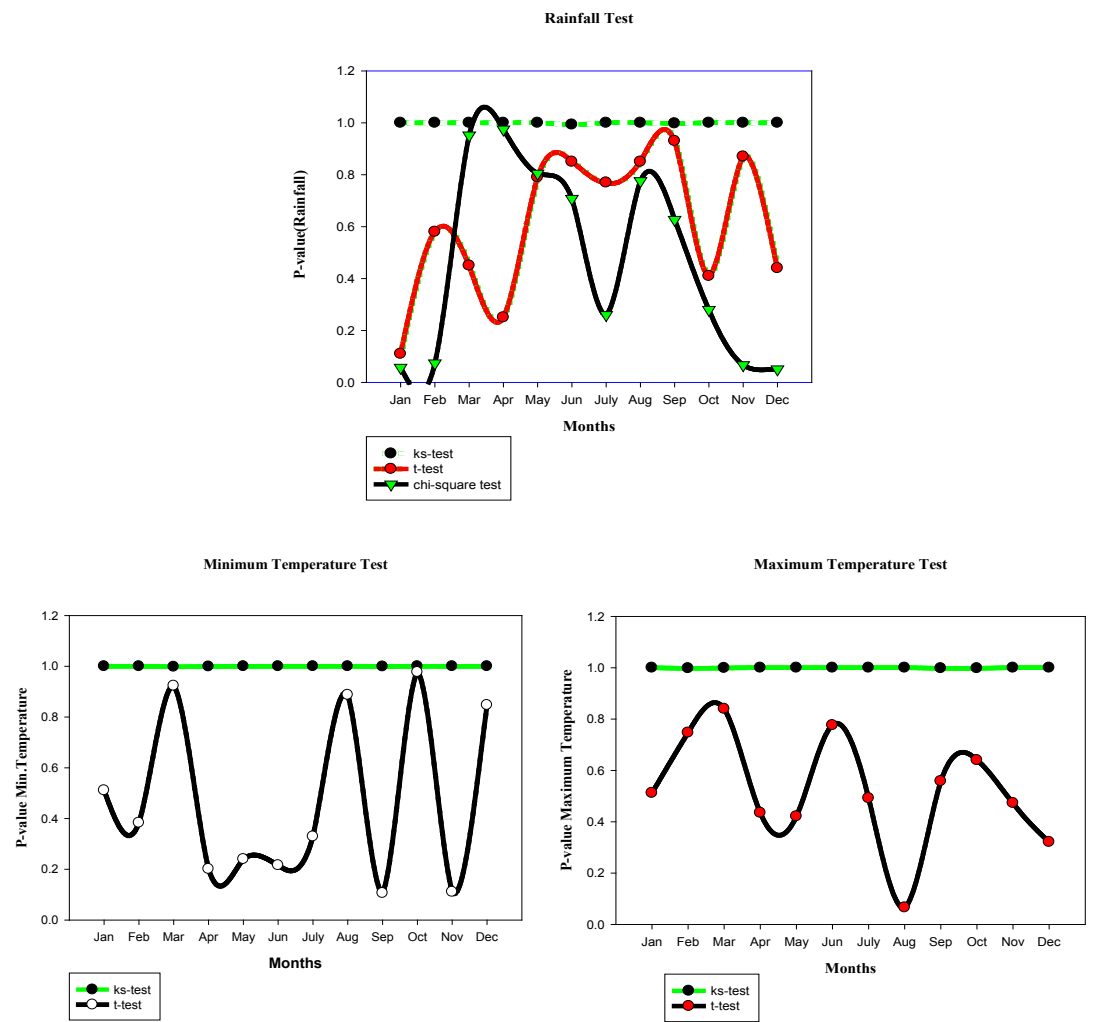

Figure 2. Plot of $\mathrm{P}$-values for $\mathrm{X}^{2}, \mathrm{~K}-\mathrm{S}$ and $\mathrm{t}$-tests for rainfall and temperatures. 

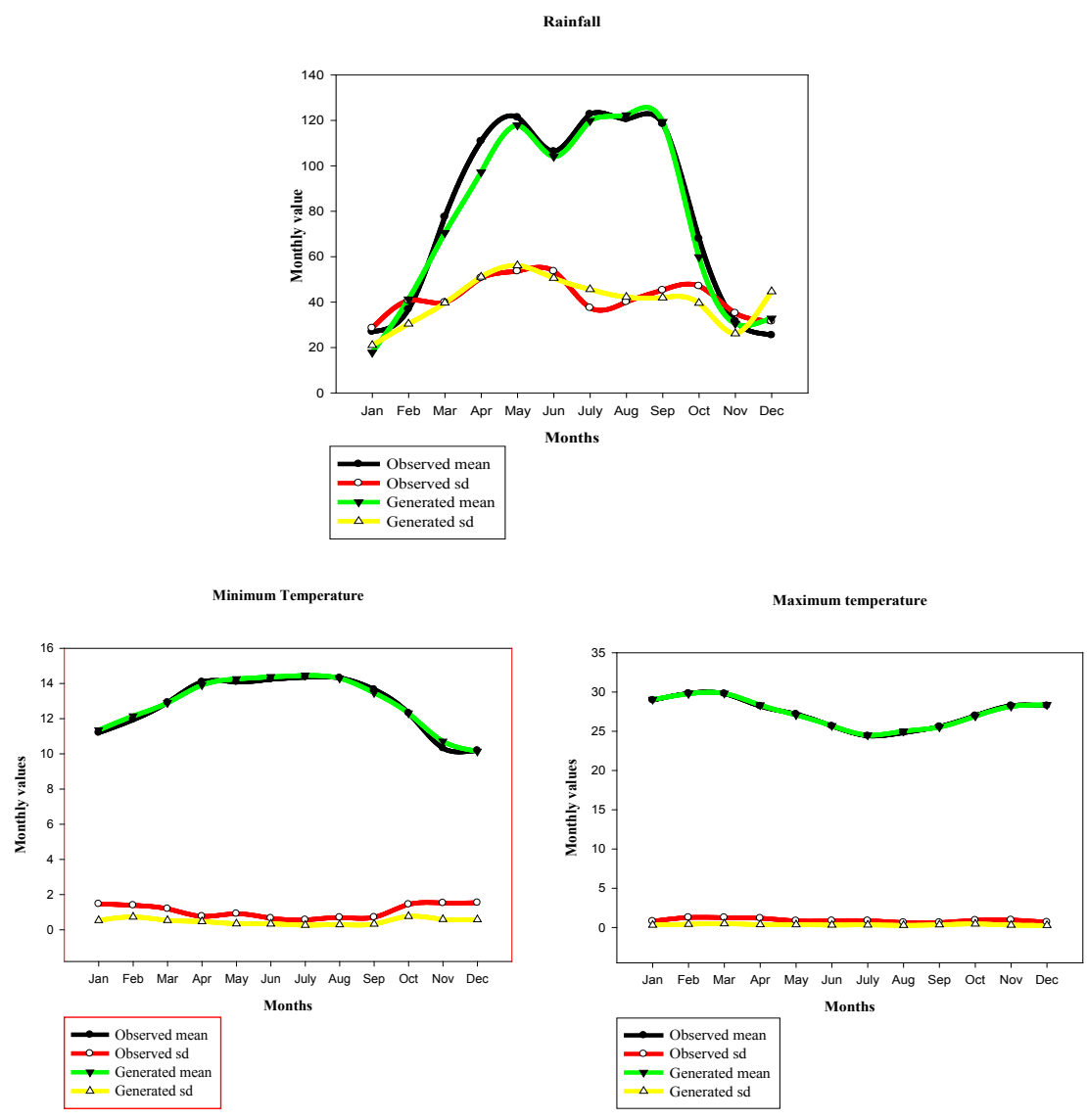

Figure 3. Comparison of generated and observed monthly weather data using mean and standard deviation.

temperature in each time horizon in each emission scenarios at different probability percentiles. The box plots indicate the lower (25\%) and upper (75\%) quartiles, the line between them is the median, and the lower and upper whiskers represent the mean \pm standard deviation. The straight line shows the historical observed mean monthly rainfall, maximum and minimum temperature based on [23]; [26]; [27]; [28]. The figures present that historical observed rainfall mean remain in the range of synthetic rainfall mean for three time horizons (2020s, 2055s and 2090s) under both emission scenarios; whereas historical observed maximum and minimum temperatures mean coming out of the ranges of synthetic generated mean temperatures in coming three time periods (2020s, 2055s, 2090) respectively which indicate that temperatures (maximum, minimum) increase is significant in coming time periods under both scenarios whilst synthetic relative rainfall increase or decrease is ambiguous in coming three time periods in each scenario. Figures 4-6 also present the 15 GCMs predictions that indicate a wide range in synthetic climate variables [23]. For instance, consider the estimated rainfall amount in the month of March estimated under emission scenario A in 2055s (SRA1B-2055s). Simulated rainfall amount by all GCMs for this month ranges approximately between $58 \mathrm{~mm}$ (BCM2) GCM model to 136 $\mathrm{mm}$ (NCPCM) GCM model where the difference is about $70 \mathrm{~mm}$. 
SRB1-2020s

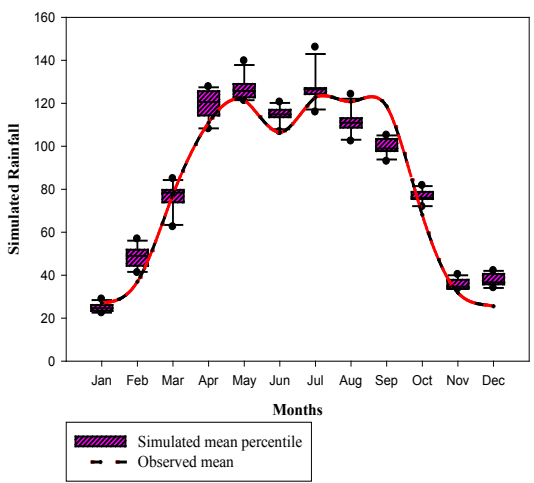

SRA1B-2055s

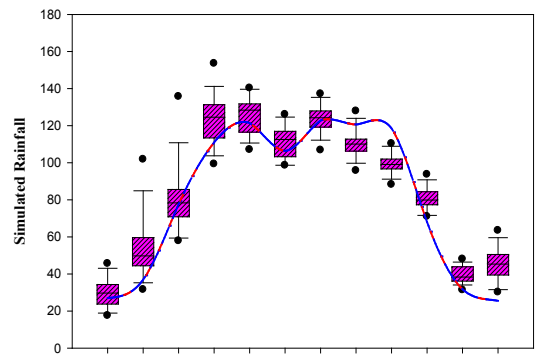

Jan Feb Mar Apr May Jun Jul Aug Sep Oct Nov Dec

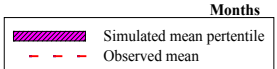

SRA1B-2090s

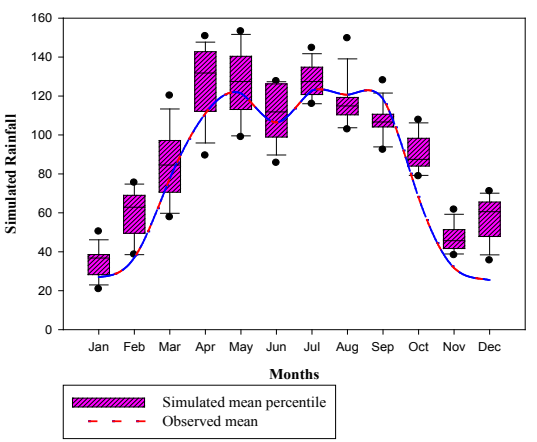

SRA1B-2020s

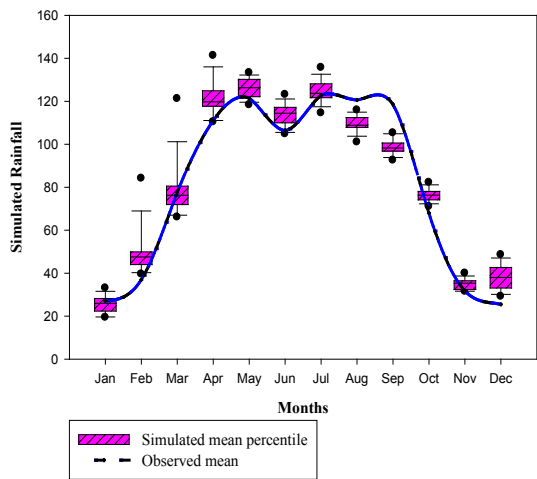

SRB1-2055s

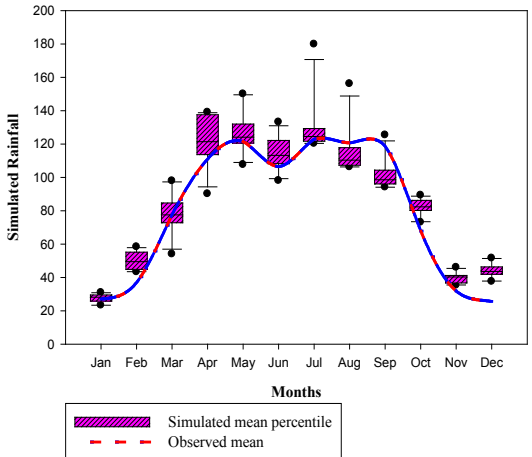

SRB1-2090s

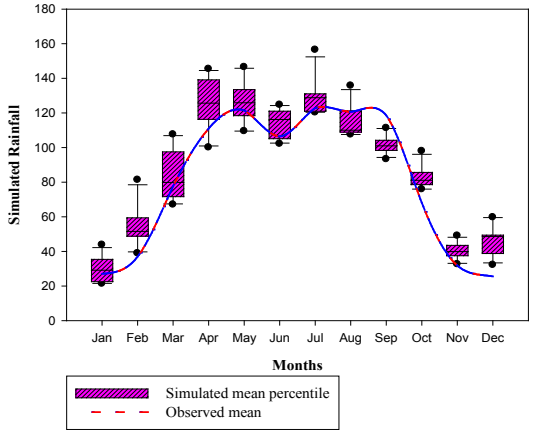

Figure 4. Box plots showing the simulated mean monthly rainfall for 15 GCMs under scenarios A and B for three different time steps.

Figures 4-6 clearly present that there are predictions variations among each 15 GCMs model for the three climate variables (maximum, minimum temperature and rainfall) but the variation is high in rainfall than temperatures. Consider the estimated maximum temperature amount in the month of June estimated under emission scenario A in 2090s (SRA1B-2090s); The simulated maximum temperature amount by all GCMs for this month ranges approximately between $27.46^{\circ} \mathrm{C}$ (GIAOM) GCM model to $30.23^{\circ} \mathrm{C}$ (MPEH5) GCM model where the difference is about $2.768^{\circ} \mathrm{C}$. Similarly simulated minimum temperature in the month of December under emission scenario B in 2090s (SRB1-2090s) by all 
SRA1B-2020s

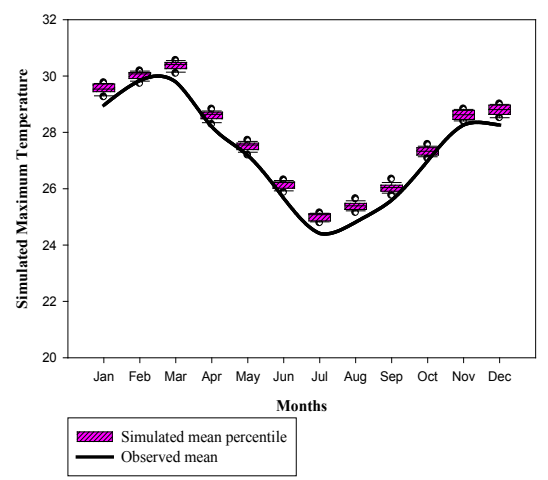

SRA1B-2055s

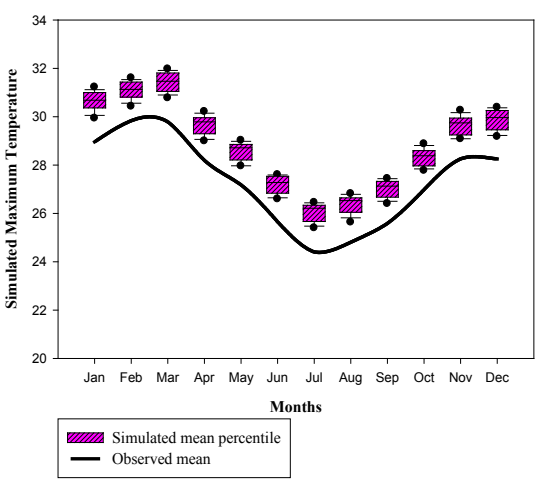

SRA1B-2090s

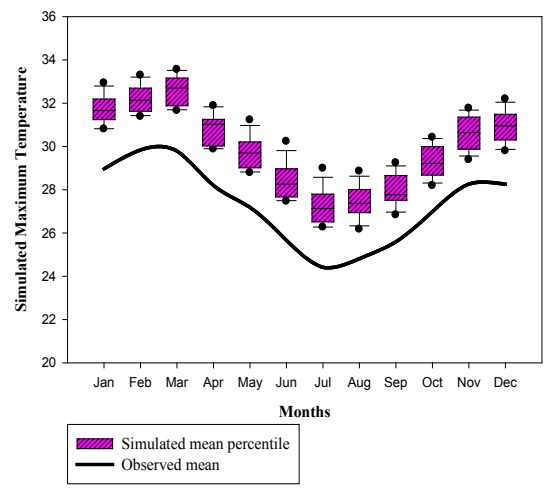

SRB1-2020s

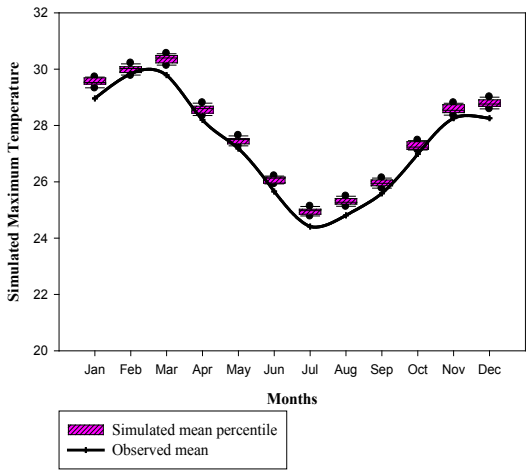

SRB1-2055s

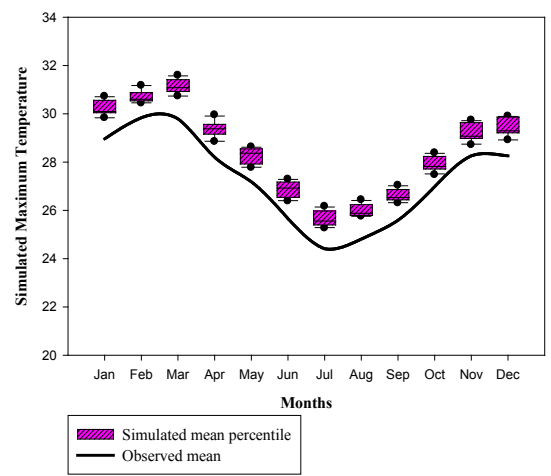

SRB1-2090s

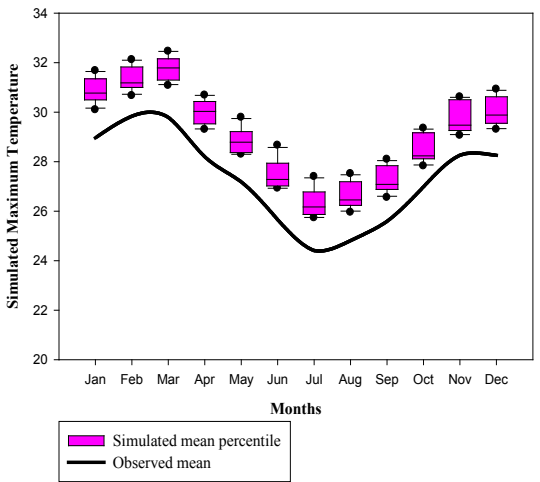

Figure 5. Box plots showing the simulated mean monthly maximum temperature for 15 GCMs under scenarios A and B for three different time steps.

GCMs ranges between $11.76^{\circ} \mathrm{C}$ (NCCCSM) GCM model to $14.02^{\circ} \mathrm{C}$ (INCM3) GCM model where the difference is about $2.25^{\circ} \mathrm{C}$. This range in magnitude of output data simply confirms the notion that output weather variables from GCMs are associated with uncertainties [23]. This phenomenon recurs in the rest of the months, scenarios and in all time periods both in simulated rainfall and minimum and maximum temperature data. It is therefore significant that such uncertainties are accounted for before outputs of GCMs are used in climate change assessment studies. 
SRA1B-2020s

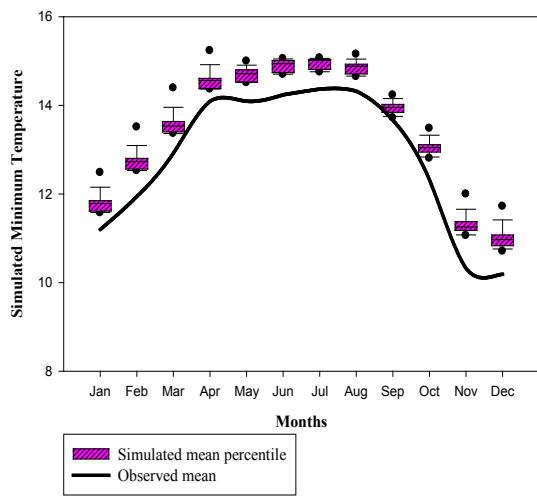

SRA1B-2055s

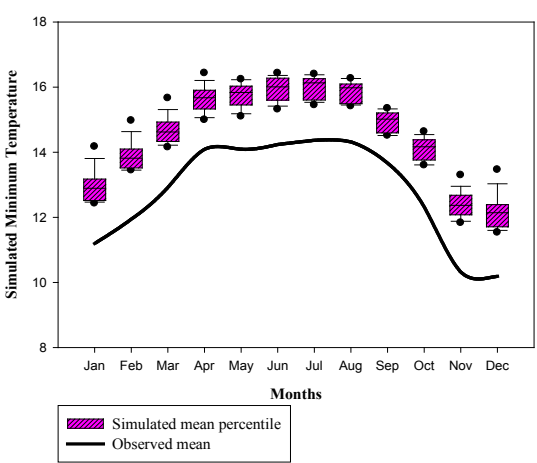

SRA1B-2090s

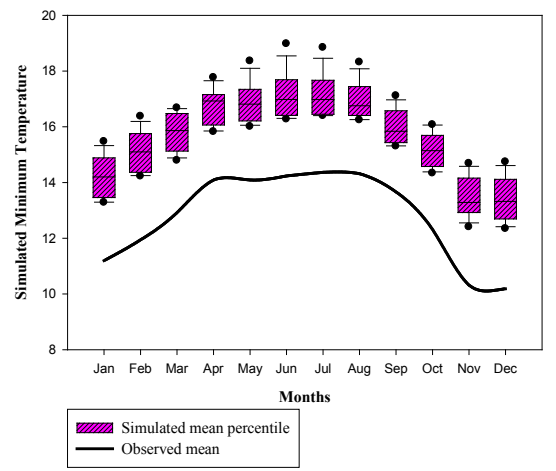

SRB1-2020s

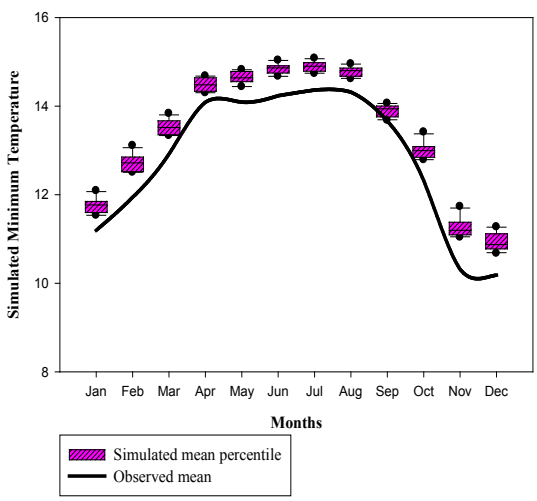

SRB1-2055s

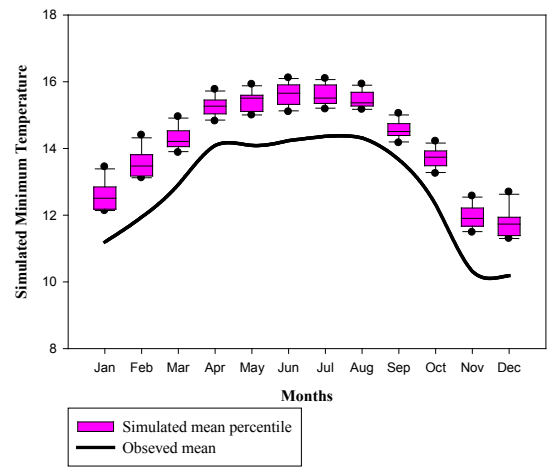

SRB1-2090s

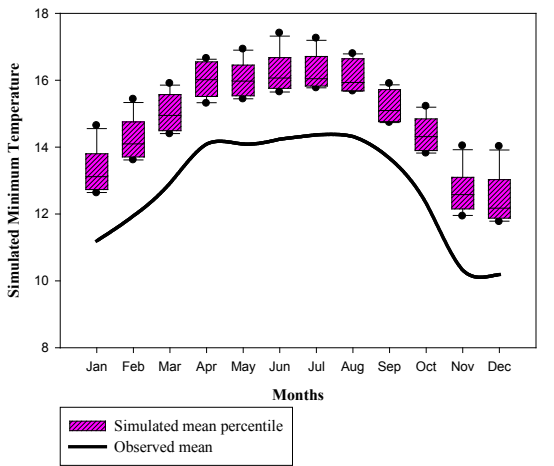

Figure 6. Box plots showing the simulated mean monthly minimum temperature for 15 GCMs under scenarios A and B for three different time periods.

\subsection{Uncertainty Analysis of GCMs}

\subsubsection{Weighting of GCMs}

Table 2 shows the weight of each GCM in simulating future changes in rainfall; Table 3 shows the weight of each GCM in simulating future changes in minimum temperature and Table 4 shows the weight of each GCM in simulating future changes in maximum temperature in each month. Generally, the expected relative precipitation changes are more uncertain about 0.83 weight differences among GCMs models whereas the relative expected temperature change among 
Table 2. Calculated weight of each GCM in simulating future rainfall.

\begin{tabular}{ccccccccccccc}
\hline & Jan & Feb & Mar & Apr & May & Jun & Jul & Aug & Sep & Oct & Nov & Dec \\
\hline BCM2 & 0.05 & 0.15 & 0.01 & 0.08 & 0.06 & 0.33 & 0.26 & 0.06 & 0.06 & 0.05 & 0.01 & 0.06 \\
CGMR & 0.02 & 0.04 & 0.26 & 0.05 & 0.03 & 0.02 & 0.02 & 0.04 & 0.05 & 0.05 & 0.01 & 0.04 \\
CNCM3 & 0.02 & 0.06 & 0.02 & 0.17 & 0.08 & 0.03 & 0.05 & 0.05 & 0.06 & 0.03 & 0.01 & 0.03 \\
CNCM3 & 0.04 & 0.11 & 0.02 & 0.12 & 0.06 & 0.17 & 0.07 & 0.05 & 0.05 & 0.09 & 0.02 & 0.09 \\
FGOALS & 0.03 & 0.04 & 0.02 & 0.03 & 0.06 & 0.04 & 0.09 & 0.05 & 0.06 & 0.03 & 0.01 & 0.04 \\
GFCM21 & 0.03 & 0.1 & 0.03 & 0.15 & 0.12 & 0.02 & 0 & 0.04 & 0.16 & 0.05 & 0.01 & 0.1 \\
GIAOM & 0.07 & 0.07 & 0.04 & 0.04 & 0.04 & 0.04 & 0.19 & 0.06 & 0.06 & 0.05 & 0.01 & 0.07 \\
HADCM3 & 0.05 & 0.04 & 0.01 & 0.03 & 0.16 & 0.07 & 0.11 & 0.06 & 0.06 & 0.06 & 0.01 & 0.05 \\
HADGEM & 0.02 & 0.16 & 0.23 & 0.06 & 0.1 & 0.07 & 0.01 & 0.03 & 0.04 & 0.22 & 0.83 & 0.2 \\
INCM3 & 0.01 & 0.03 & 0.02 & 0.04 & 0.05 & 0.03 & 0.01 & 0.16 & 0.07 & 0.03 & 0.01 & 0.04 \\
IPCM4 & 0.44 & 0.06 & 0.04 & 0.03 & 0.02 & 0.02 & 0.02 & 0.07 & 0.08 & 0.05 & 0.01 & 0.05 \\
MIHR & 0.02 & 0.04 & 0.09 & 0.03 & 0.02 & 0.02 & 0.07 & 0.05 & 0.06 & 0.05 & 0.01 & 0.04 \\
MPEH5 & 0.13 & 0.05 & 0.09 & 0.11 & 0.1 & 0.08 & 0.04 & 0.18 & 0.09 & 0.05 & 0.01 & 0.06 \\
NCCCSM & 0.06 & 0.05 & 0.13 & 0.05 & 0.05 & 0.02 & 0.01 & 0.06 & 0.05 & 0.06 & 0.01 & 0.05 \\
NCPCM & 0.01 & 0.01 & 0 & 0.02 & 0.05 & 0.05 & 0.04 & 0.04 & 0.05 & 0.13 & 0.04 & 0.08 \\
\hline
\end{tabular}

Table 3. Calculated weight of each GCM in simulating future minimum temperature.

\begin{tabular}{|c|c|c|c|c|c|c|c|c|c|c|c|c|}
\hline & Jan & Feb & Mar & Apr & May & June & July & Aug & Sept & Oct & Nov & Dec \\
\hline BCM2 & 0.06 & 0.06 & 0.06 & 0.06 & 0.07 & 0.07 & 0.07 & 0.07 & 0.07 & 0.07 & 0.07 & 0.07 \\
\hline CGMR & 0.05 & 0.06 & 0.06 & 0.05 & 0.05 & 0.05 & 0.05 & 0.04 & 0.04 & 0.05 & 0.06 & 0.06 \\
\hline CNCM3 & 0.05 & 0.05 & 0.05 & 0.05 & 0.05 & 0.05 & 0.05 & 0.05 & 0.04 & 0.05 & 0.05 & 0.05 \\
\hline CSMK3 & 0.08 & 0.08 & 0.08 & 0.08 & 0.08 & 0.08 & 0.08 & 0.09 & 0.10 & 0.09 & 0.08 & 0.08 \\
\hline FGOALS & 0.09 & 0.08 & 0.08 & 0.09 & 0.09 & 0.08 & 0.08 & 0.08 & 0.08 & 0.08 & 0.09 & 0.09 \\
\hline GFCM21 & 0.06 & 0.06 & 0.06 & 0.05 & 0.06 & 0.06 & 0.06 & 0.07 & 0.06 & 0.06 & 0.07 & 0.06 \\
\hline GIAOM & 0.08 & 0.08 & 0.08 & 0.08 & 0.08 & 0.08 & 0.08 & 0.08 & 0.09 & 0.08 & 0.07 & 0.08 \\
\hline HADCM3 & 0.06 & 0.06 & 0.06 & 0.06 & 0.05 & 0.05 & 0.05 & 0.06 & 0.05 & 0.06 & 0.06 & 0.06 \\
\hline HADGEM & 0.09 & 0.09 & 0.09 & 0.09 & 0.08 & 0.08 & 0.07 & 0.07 & 0.08 & 0.08 & 0.09 & 0.08 \\
\hline INCM3 & 0.04 & 0.04 & 0.04 & 0.04 & 0.05 & 0.05 & 0.06 & 0.06 & 0.06 & 0.05 & 0.04 & 0.04 \\
\hline IPCM4 & 0.05 & 0.05 & 0.05 & 0.05 & 0.05 & 0.05 & 0.05 & 0.05 & 0.05 & 0.05 & 0.05 & 0.06 \\
\hline MIHR & 0.04 & 0.05 & 0.05 & 0.04 & 0.05 & 0.05 & 0.05 & 0.05 & 0.04 & 0.05 & 0.05 & 0.05 \\
\hline MPEH5 & 0.05 & 0.06 & 0.05 & 0.05 & 0.05 & 0.04 & 0.04 & 0.05 & 0.05 & 0.05 & 0.06 & 0.06 \\
\hline NCCCSM & 0.08 & 0.08 & 0.08 & 0.07 & 0.07 & 0.08 & 0.07 & 0.07 & 0.07 & 0.07 & 0.07 & 0.08 \\
\hline NCPCM & 0.11 & 0.10 & 0.11 & 0.13 & 0.12 & 0.12 & 0.12 & 0.11 & 0.13 & 0.10 & 0.09 & 0.10 \\
\hline
\end{tabular}


Table 4. Calculated weight of each GCM in simulating future maximum temperature.

\begin{tabular}{|c|c|c|c|c|c|c|c|c|c|c|c|c|}
\hline & Jan & Feb & Mar & Apr & May & June & July & Aug & Sept & Oct & Nov & Dec \\
\hline BCM2 & 0.08 & 0.06 & 0.05 & 0.05 & 0.05 & 0.06 & 0.06 & 0.07 & 0.07 & 0.08 & 0.09 & 0.09 \\
\hline CGMR & 0.05 & 0.05 & 0.06 & 0.05 & 0.05 & 0.05 & 0.05 & 0.04 & 0.04 & 0.04 & 0.04 & 0.05 \\
\hline CNCM3 & 0.05 & 0.04 & 0.05 & 0.04 & 0.05 & 0.05 & 0.05 & 0.05 & 0.04 & 0.04 & 0.04 & 0.04 \\
\hline CSMK3 & 0.07 & 0.07 & 0.07 & 0.07 & 0.07 & 0.07 & 0.07 & 0.07 & 0.07 & 0.08 & 0.08 & 0.07 \\
\hline FGOALS & 0.08 & 0.08 & 0.08 & 0.08 & 0.09 & 0.08 & 0.08 & 0.08 & 0.08 & 0.08 & 0.08 & 0.08 \\
\hline GFCM21 & 0.05 & 0.05 & 0.05 & 0.05 & 0.05 & 0.06 & 0.06 & 0.07 & 0.06 & 0.06 & 0.05 & 0.05 \\
\hline GIAOM & 0.10 & 0.11 & 0.09 & 0.10 & 0.10 & 0.09 & 0.09 & 0.09 & 0.09 & 0.09 & 0.09 & 0.10 \\
\hline HADCM3 & 0.05 & 0.05 & 0.06 & 0.05 & 0.05 & 0.05 & 0.05 & 0.05 & 0.05 & 0.05 & 0.05 & 0.05 \\
\hline HADGEM & 0.08 & 0.10 & 0.09 & 0.09 & 0.08 & 0.08 & 0.07 & 0.07 & 0.07 & 0.08 & 0.08 & 0.08 \\
\hline INCM3 & 0.08 & 0.08 & 0.08 & 0.08 & 0.07 & 0.08 & 0.09 & 0.10 & 0.10 & 0.10 & 0.11 & 0.09 \\
\hline IPCM4 & 0.05 & 0.04 & 0.05 & 0.05 & 0.05 & 0.05 & 0.05 & 0.05 & 0.05 & 0.04 & 0.04 & 0.05 \\
\hline MIHR & 0.05 & 0.04 & 0.05 & 0.04 & 0.04 & 0.05 & 0.05 & 0.05 & 0.04 & 0.04 & 0.04 & 0.05 \\
\hline MPEH5 & 0.05 & 0.05 & 0.05 & 0.05 & 0.04 & 0.04 & 0.04 & 0.05 & 0.05 & 0.05 & 0.04 & 0.05 \\
\hline NCCCSM & 0.07 & 0.07 & 0.07 & 0.07 & 0.07 & 0.08 & 0.07 & 0.07 & 0.07 & 0.07 & 0.06 & 0.07 \\
\hline NCPCM & 0.10 & 0.12 & 0.10 & 0.13 & 0.14 & 0.13 & 0.11 & 0.11 & 0.11 & 0.10 & 0.09 & 0.09 \\
\hline
\end{tabular}

GCMs is about 0.09 weight difference. This result shows that LARS WG 5.5 model is more certain to generate statistically monthly absolute mean temperatures than generating monthly relative mean rainfall [23].

\subsubsection{Probability Distribution Functions (PDFs)}

Figures 7-9 show sample monthly discrete PDFs for the 15 GMs under scenarios A (SRA1B) and B (SRB1) against weight of each model to simulate climate variables in coming three time horizons [23]. For instance, first figure under Figure 7 shows relative rainfall change against GCMs weight for the month of March for the period of 2020s under scenario SRA1B. The figure shows that big rainfall changes from 0.8 to 1.2 ranges in GCM weight of 0 to 0.1 .

\subsubsection{Cumulative Distribution Functions (CDFs)}

In this step, the developed PDFs are converted to CDFs [23], [29], [30] using gamma distribution function with two parameters. Here, exceedance probability curves or CDFs can be developed based on the constructed PDFs from Figures 7-9 for Figures 10-12.

\subsection{Generation of Probability Percentiles}

The magnitude of the expected changes in rainfall, minimum and maximum temperature at three different probability percentiles (25\%, 50\% and $75 \%)$, were determined from the synthetic CDFs for both scenarios (SRA1B and SRB1) and in three time steps (2020s, 2055s and 2090s). Figure 13 shows the expected changes in future rainfall amounts under two scenarios [23]. The simulated 
SRA1B-2020s,March

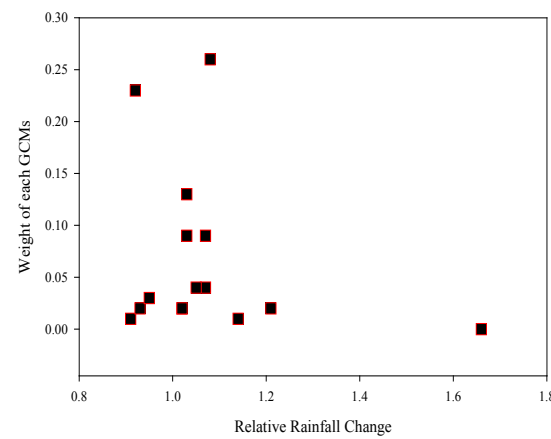

SRA1B-2055s,July

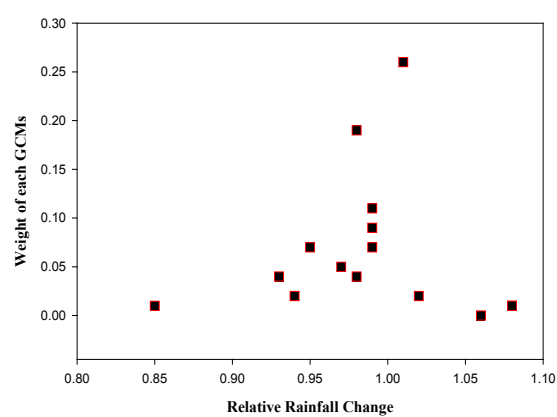

SRB1-2020s,Feb

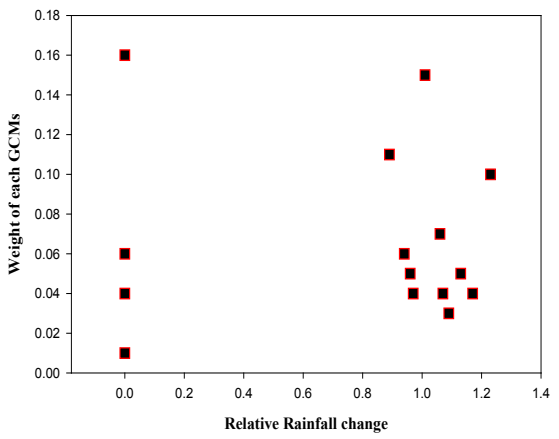

SRA1B-2090s,July

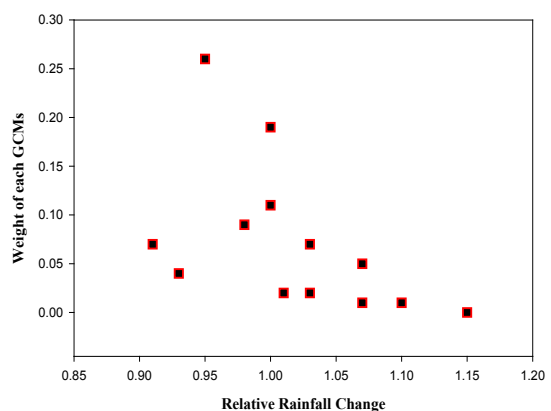

Figure 7. Sample Discrete PDFs outlining the relationship between weights of 15 GCMs and monthly changes in relative rainfall.
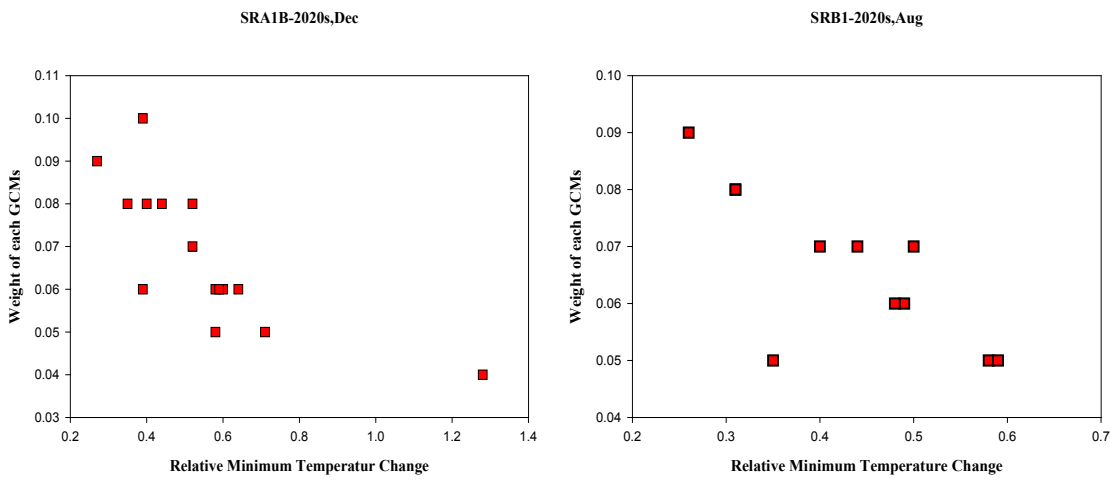

SRA1B-2055s,Dec

SRA1B-2090s,Dec
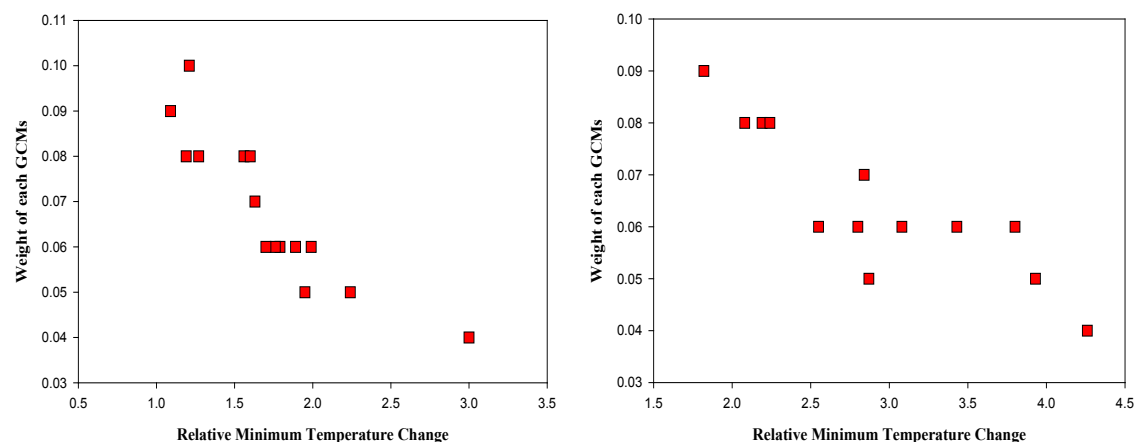

Figure 8. Sample Discrete PDFs outlining the relationship between weights of 15 GCMs and monthly changes in relative minimum temperature. 
SRA1B-2020s,May

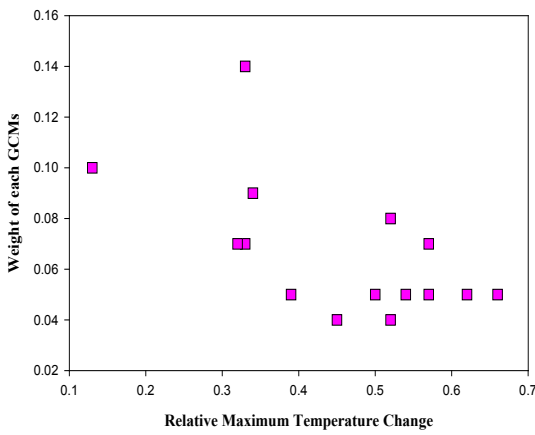

SRA1B-2090s,May

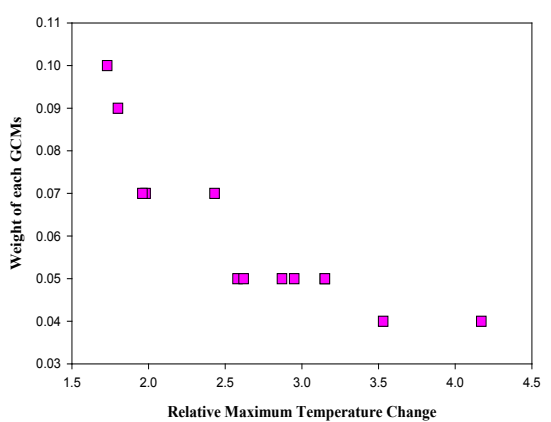

SRA1B-2055s,May

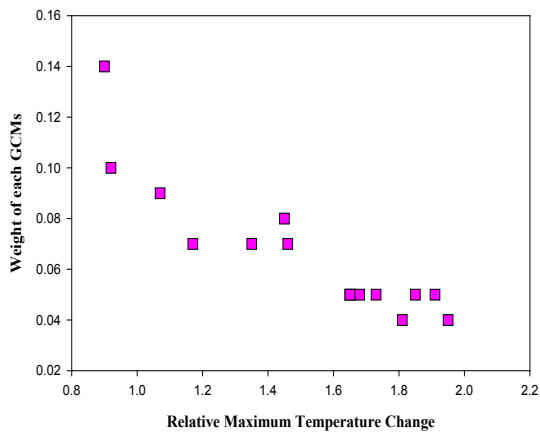

SRB1-2090s,Sept

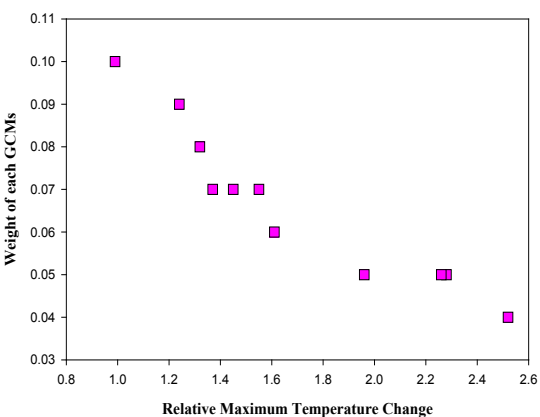

Figure 9. Sample Discrete PDFs outlining the relationship between weights of 15 GCMs and monthly changes in relative maximum temperature.

SRB1-2020s,Feb

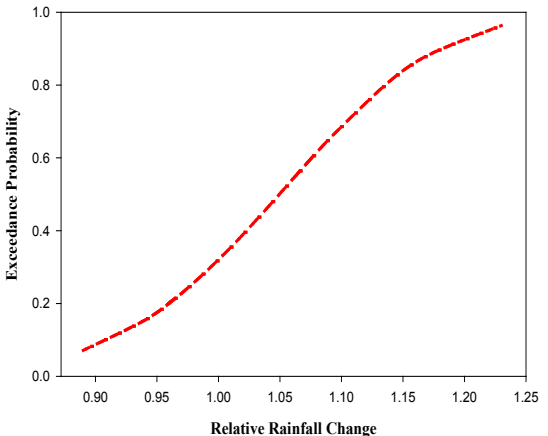

SRA1B-2055s,July

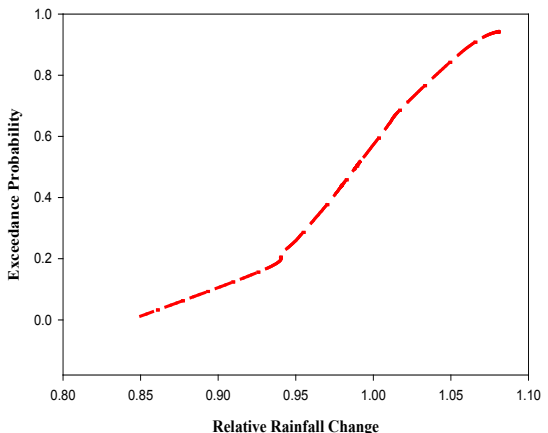

SRA1B-2020s, March

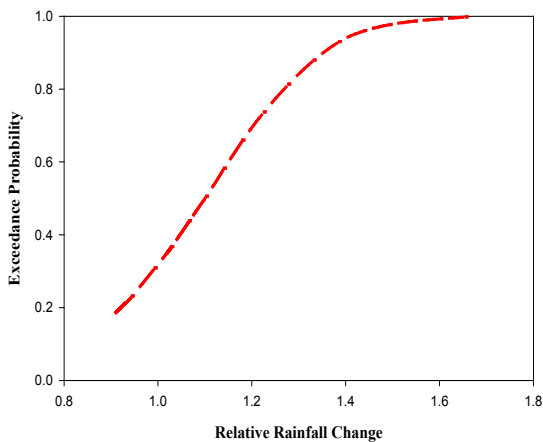

SRA1B-2090s,July

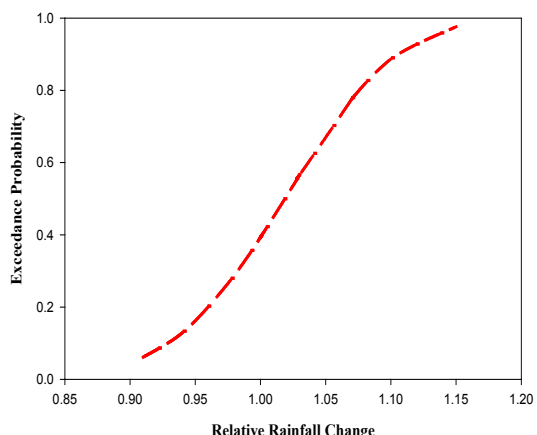

Figure 10. Sample CDFs for rainfall based on sample PDFs shown above under Figure 7. 
SRA1B-2020s,Oct

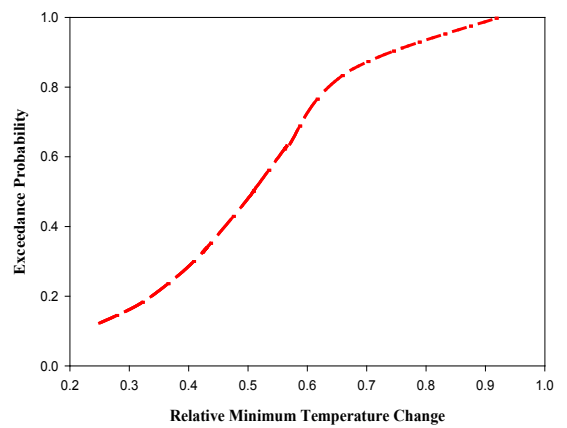

SRA1B-2055s,Dec

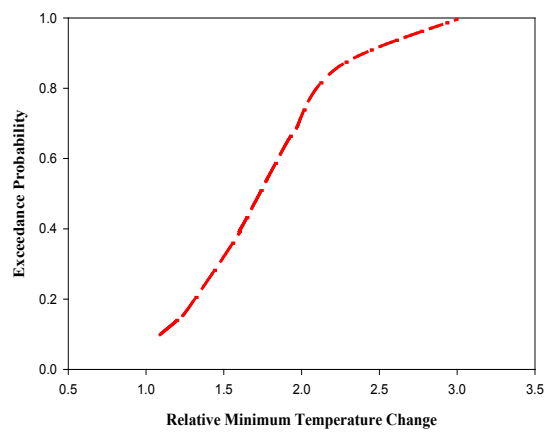

SRB1-2020s,Aug

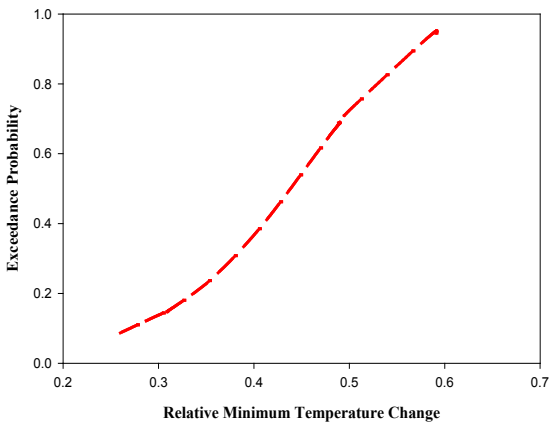

SRA1B-2090s,Dec

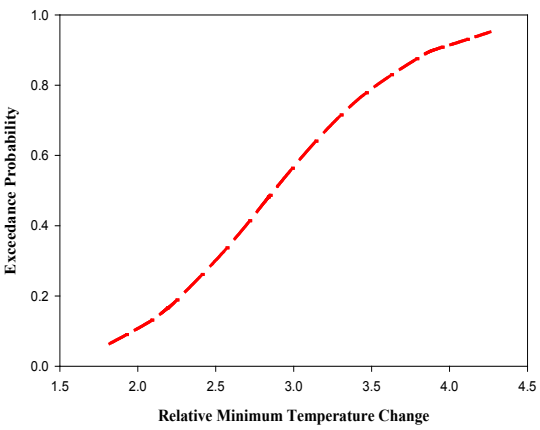

Figure 11. Sample CDFs for minimum temperature based on sample PDFs shown above under Figure 8.

SRA1B-2055s,May

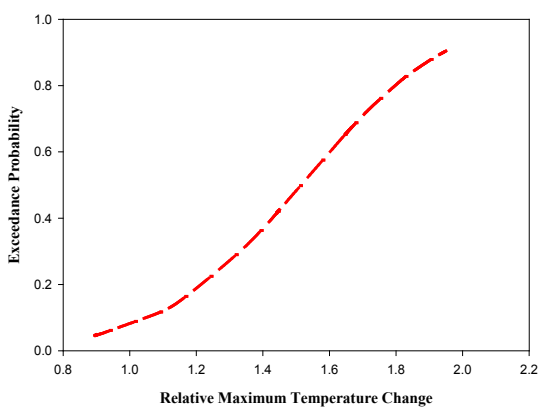

SRA1B-2090s,May

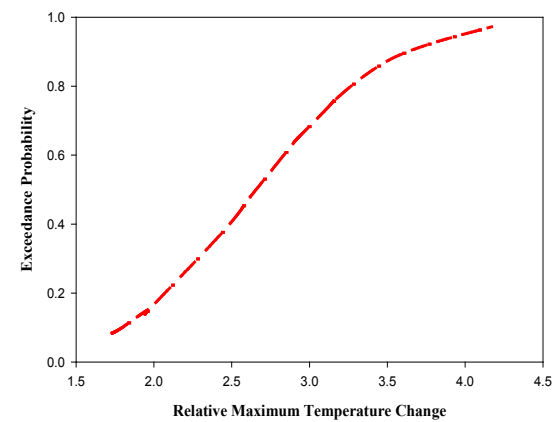

SRA1B-2020s,May

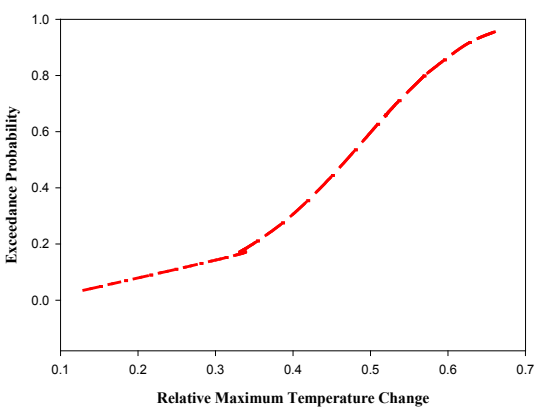

SRA1B-2090s,Sept

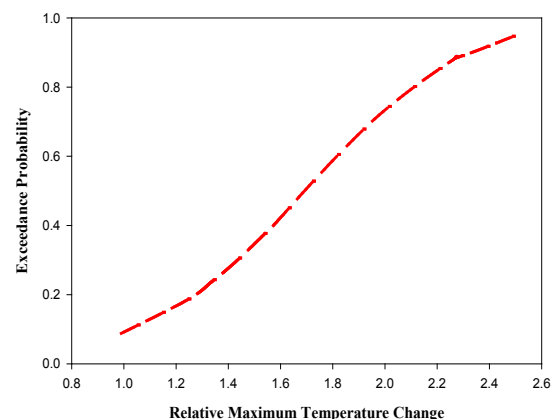

Figure 12. Sample CDFs for max temperature based on sample PDFs shown above under Figure 9. 
SRA1B-2020s

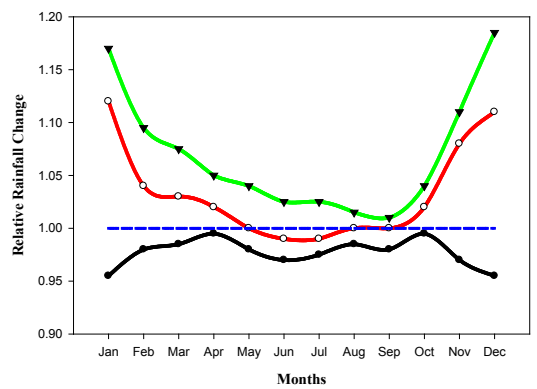

$$
\begin{aligned}
& 75 \% \text { probability percentile } \\
& -20-50 \% \text { probability percentile }
\end{aligned}
$$
$25 \%$ probability percentile

SRA1B-2055s

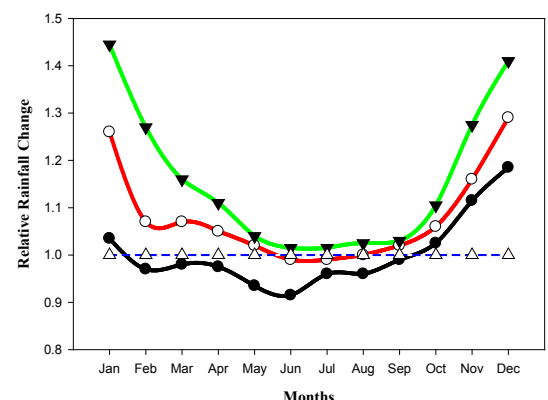

$$
\longrightarrow \text { - } 75 \% \text { probability percentile }
$$$$
\checkmark 25 \% \text { probability percentil }
$$

SRA1B-2090s

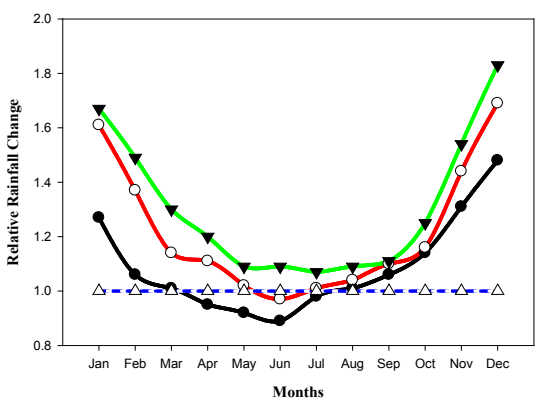
Months

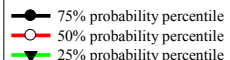

SRB1-2020s

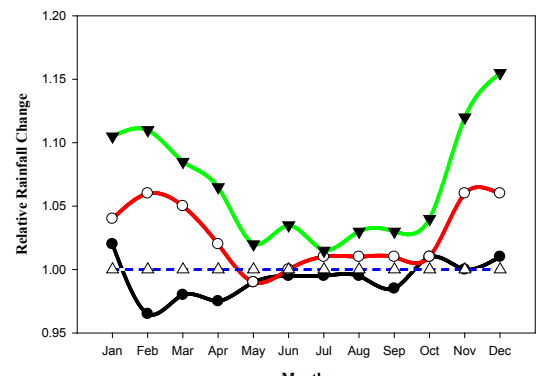

Months

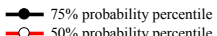
$5 \%$ probability percentile $25 \%$ probability percentile

SRB1-2055s

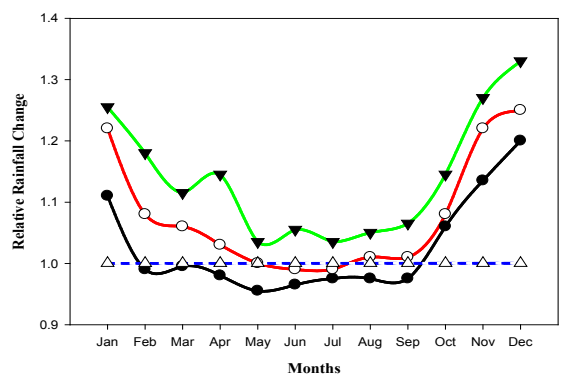

\section{$\because-75 \%$ probability percentile} $50 \%$ probability percentile
$25 \%$ probability percentile

SRB1-2090s

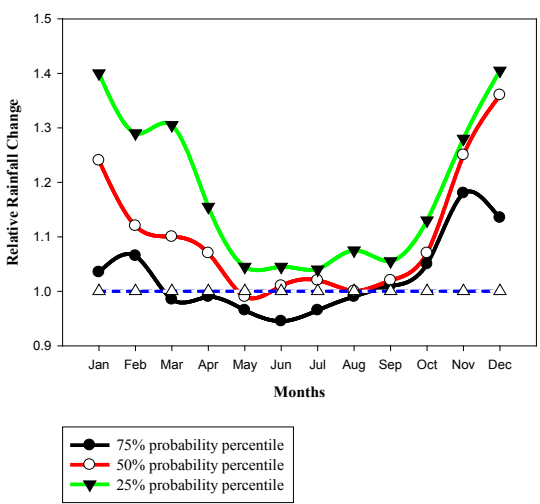

Figure 13. The estimated future changes in relative rainfall at three probability percentiles.

results show that higher rainfall changes are expected under scenario A than scenario B in all three time periods except in period 2055s at $25 \%$ probability percentile. The expected changes in monthly rainfall for each time period varies between risk levels. Results indicate high increase in rainfall in some months like December, January, and February (DJF) which is winter ("bega") season of the country. The United Nations Development Programme (UNDP) country profile study projections consistently indicate increases in annual rainfall in Ethiopia, 
largely due to increased rain in the short rainy season of October-December in southern Ethiopia [31] that supports this study. However, some months of year like May to August indicate low increase in rainfall under both scenarios for three time periods at each risk level and very low rainfall increase is generated in summer ("kiremt") season of the country from June to August (JJA). Table 5 under shows the general seasonal rainfall variability at each time period under both emission scenarios at three probability percentile. On average, summer rainfall amounts are expected to increase and/or decrease with the ranges of $-2.34 \%$ to $2.67 \%,-5.5 \%$ to $4.67 \%$ and $-4 \%$ to $8.34 \%$ in 2020 s, 2050 s and 2090 s respectively and winter rainfall amounts are expected to increase and/or decrease with ranges $-3.67 \%$ to $15 \%, 6.34 \%$ to $37.5 \%$ and $7.84 \%$ to $66.34 \%$ in 2020s, 2050s and 2090s respectively. However, overall mean monthly rainfall generation indicates that rainfall will increase in the study area in range of $-2.3 \%$ to $7 \%, 0.375 \%$ to $15.83 \%$ and $2.625 \%$ to $31.0 \%$ in three time periods $2020 \mathrm{~s}, 2055 \mathrm{~s}$ and 2090s respectively. Ethiopia national meteorological agency (NMA) released climate projections for Ethiopia that has been generated using the software MAGICC/SCENGEN (Model for the Assessment of Greenhouse-gas Induced Climate Change)/(Regional and global Climate SCENario GENerator) coupled model (Version 4.1) for three periods centered on the years 2030, 2050 and 2080. Rainfall prediction for coming three time periods based on 19 GCMs models for different parts of the country under scenario A1B and B1 with relative to baseline period of 1961-1990 normal. The study result outlined that rainfall projections from different models in the ensemble are broadly consistent in indicating increases in annual rainfall in Ethiopia. However these increases are likely to occur in the October, November and December rainfall season (OND) in southern Ethiopia and in an increasing amount of rainfall occurring in "heavy events." Annual changes in heavy events range from $-1 \%$ to $+18 \%$. The largest increases are seen in JAS and OND rainfall [27]. Projections of change in the

Table 5. Seasonal rainfall variability output under each scenario and in each time horizons at different risk levels.

\begin{tabular}{cccccccccc}
\hline \multirow{2}{*}{ Periods } & \multirow{2}{*}{ Seasons } & \multicolumn{3}{c}{ Scenario A } & \multicolumn{3}{c}{ Scenario B } & \multirow{2}{*}{ Range } \\
\cline { 3 - 8 } & & $25 \mathrm{~A}$ & $50 \mathrm{~A}$ & $75 \mathrm{~A}$ & $25 \mathrm{~B}$ & $50 \mathrm{~B}$ & $75 \mathrm{~B}$ & & \\
\hline \multirow{3}{*}{ 2020s } & DJF ('bega') & -3.67 & 9 & 15 & -0.17 & 5.34 & 12.34 & -3.67 & 15 \\
& MAM ('belg') & -1.34 & 1.67 & 5.5 & -1.84 & 2 & 5.67 & -1.87 & 5.67 \\
& JJA ('kiremt') & -2.34 & -0.67 & 2.17 & -0.5 & 0.67 & 2.67 & -2.34 & 2.67 \\
& SON ('tseday') & -1.84 & 3.34 & 5.34 & -0.17 & 2.67 & 6.34 & -1.84 & 6.34 \\
\hline \multirow{3}{*}{$2055 s$ s } & DJF ('bega') & 6.34 & 20.67 & 37.5 & 10 & 18.34 & 25.5 & 6.34 & 37.5 \\
& MAM ('belg') & -3.67 & 4.67 & 10.34 & -2.34 & 3 & 9.84 & -3.67 & 10.34 \\
& JJA ('kiremt') & -5.5 & -0.67 & 1.84 & -2.84 & 0.34 & 4.67 & -5.5 & 4.67 \\
& SON ('tseday') & 4.34 & 8 & 13.67 & 5.67 & 10.34 & 16 & 4.34 & 16 \\
\hline \multirow{2}{*}{$2090 s$} & DJF ('bega') & 27 & 55.67 & 66.34 & 7.84 & 24 & 36.5 & 7.84 & 66.34 \\
& MAM ('belg') & -4 & 9 & 19.67 & -2 & 5.34 & 16.84 & -4 & 19.67 \\
& JJA ('kiremt') & -4 & 0.67 & 8.34 & -3.34 & 1 & 5.34 & -4 & 8.34 \\
& SON ('tseday') & 17 & 20.34 & 30 & 8 & 11.34 & 15.5 & 8 & 30 \\
\hline
\end{tabular}


rainy seasons April, May, June (AMJ) and July, August, September (JAS) rainfall seasons which affect the larger portions of Ethiopia are more mixed, but tend towards slight increases in the south west and deceases in the north east [32] which rely the result of this study. Figures 13-15 present estimated future changes in rainfall, maximum temperature and minimum temperature at three probability percentiles.

Figure 14 and Figure 15 are plots of minimum and maximum temperatures for scenarios A and B under three percentiles at three time periods. Overall, temperature is expected to increase in all cases, with higher temperature changes expected under scenario $\mathrm{A}$ than in scenario $\mathrm{B}$. The mean annual temperature is projected to increase by $1.1^{\circ} \mathrm{C}$ to $3.1^{\circ} \mathrm{C}$ by the $2060 \mathrm{~s}$, and $1.5^{\circ} \mathrm{C}$ to $5.1^{\circ} \mathrm{C}$ by the 2090s [31]. Absolute values for changes in minimum temperature for $2020 \mathrm{~s}$, 2055s and 2090s are $0.34^{\circ} \mathrm{C}$ to $0.58^{\circ} \mathrm{C}, 0.94^{\circ} \mathrm{C}$ to $1.8^{\circ} \mathrm{C}$ and $1.42^{\circ} \mathrm{C}$ to $3.2^{\circ} \mathrm{C}$ respectively. Similarly, changes in maximum temperature for the same time periods were estimated as follows; $0.32^{\circ} \mathrm{C}$ to $0.56^{\circ} \mathrm{C}, 0.91^{\circ} \mathrm{C}$ to $1.8^{\circ} \mathrm{C}$ and $1.34^{\circ} \mathrm{C}$ to $3.035^{\circ} \mathrm{C}$ respectively.

The same study released by national meteorological agency (NMA) of Ethiopia as explained above for rainfall using the IPCC mid-range (A1B) emission scenario, the mean annual temperature will increase in the range of $0.9^{\circ} \mathrm{C}$ $1.1^{\circ} \mathrm{C}$ by 2030 , in the range of $1.7^{\circ} \mathrm{C}-2.1^{\circ} \mathrm{C}$ by 2050 and in the range of $2.7^{\circ} \mathrm{C}-$ $3.4^{\circ} \mathrm{C}$ by 2080 over Ethiopia compared to the baseline 1961-1990 normal. Other sources of data have also substantiated the variability of climate and its trends in a somewhat similar way. Historical climate analysis for Ethiopia indicates that mean annual temperature has increased by $1.3^{\circ} \mathrm{C}$ between 1960 and 2006, an average rate of $0.28^{\circ} \mathrm{C}$ per decade. The result of the study also declared that an increase in temperature in Ethiopia has been most rapid in June, August and September at a rate of $0.32^{\circ} \mathrm{C}$ per decade [32] whereas the result of this study indicates rapid temperature increase is simulated in December, January and March. A summary of average changes in precipitation, minimum and maximum temperature for each scenario and time period is shown in Table 6 .

Table 6. Summary of mean annual and overall ranges of estimated climate variables in each time period, at different scenarios and probability percentiles.

\begin{tabular}{|c|c|c|c|c|c|c|c|c|c|}
\hline \multirow{2}{*}{ Climate Variable } & \multirow{2}{*}{$\begin{array}{l}\text { Scenario } \\
\text { percentile }\end{array}$} & \multicolumn{3}{|c|}{ A } & \multicolumn{3}{|c|}{ B } & \multirow{2}{*}{\multicolumn{2}{|c|}{ Range }} \\
\hline & & $25 \mathrm{~A}$ & $50 \mathrm{~A}$ & $75 \mathrm{~A}$ & $25 B$ & $50 \mathrm{~B}$ & $75 B$ & & \\
\hline \multirow{3}{*}{$\begin{array}{c}\text { Rainfall } \\
\text { Change (\%) }\end{array}$} & 2020 & 7 & 3.33 & -2.3 & 6.75 & 2.67 & 0.67 & -2.3 & 7 \\
\hline & 2055 & 15.83 & 8.17 & 0.375 & 14 & 7.83 & 2.625 & 0.375 & 15.83 \\
\hline & 2090 & 31.1 & 22.17 & 9 & 18.54 & 10.42 & 2.625 & 2.625 & 31.1 \\
\hline Minimum & 2020 & 0.37 & 0.51 & 0.58 & 0.34 & 0.45 & 0.55 & 0.34 & 0.58 \\
\hline Temperature & 2055 & 1.3 & 1.6 & 1.8 & 0.94 & 1.18 & 1.4 & 0.94 & 1.8 \\
\hline Change $\left({ }^{\circ} \mathrm{C}\right)$ & 2090 & 2.11 & 2.67 & 3.2 & 1.42 & 1.75 & 2.29 & 1.42 & 3.2 \\
\hline Maximum & 2020 & 0.33 & 0.47 & 0.56 & 0.32 & 0.41 & 0.5 & 0.32 & 0.56 \\
\hline Temperature & 2055 & 1.18 & 1.58 & 1.8 & 0.91 & 1.04 & 1.36 & 0.91 & 1.8 \\
\hline Change $\left({ }^{\circ} \mathrm{C}\right)$ & 2090 & 1.98 & 2.54 & 3.035 & 1.34 & 1.6 & 2.14 & 1.34 & 3.035 \\
\hline
\end{tabular}


SRA1B-2020s

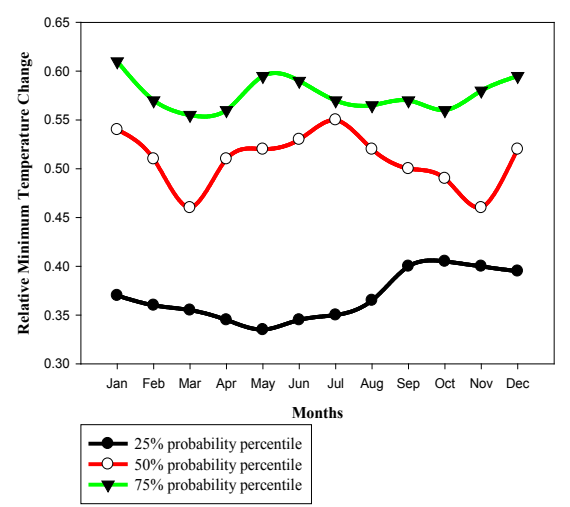

SRA1B-2055s

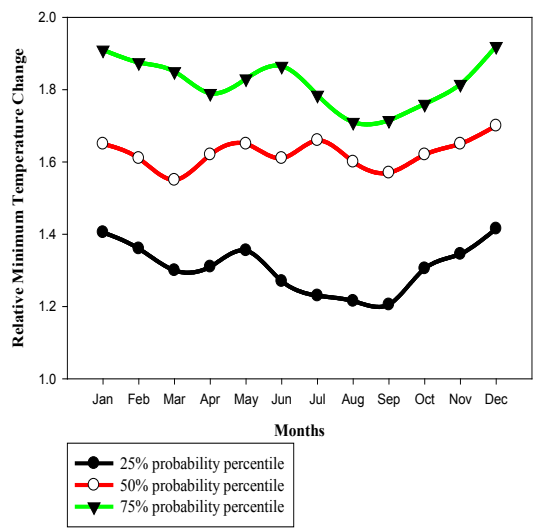

SRA1B-2090s

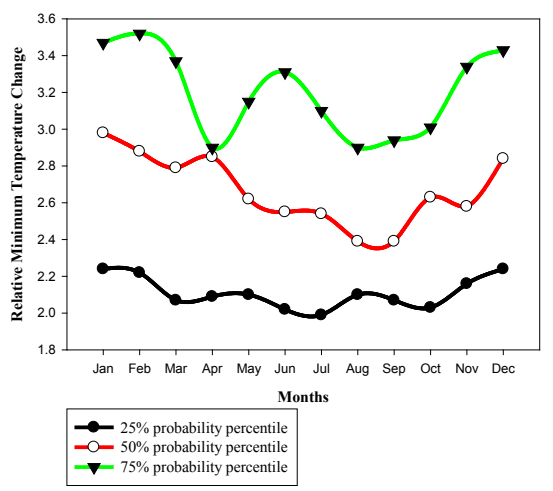

SRB1-2020s

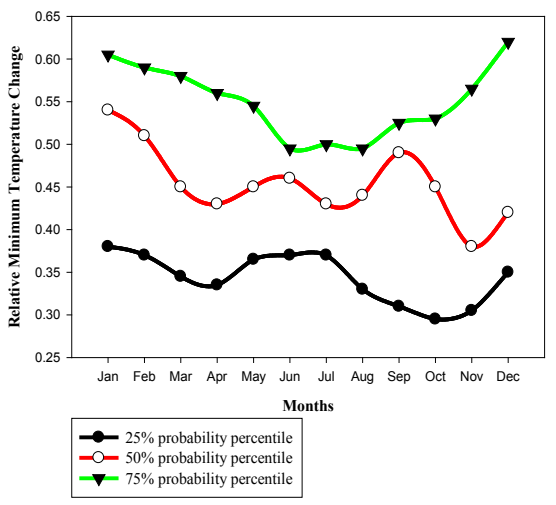

SRB1-2055s

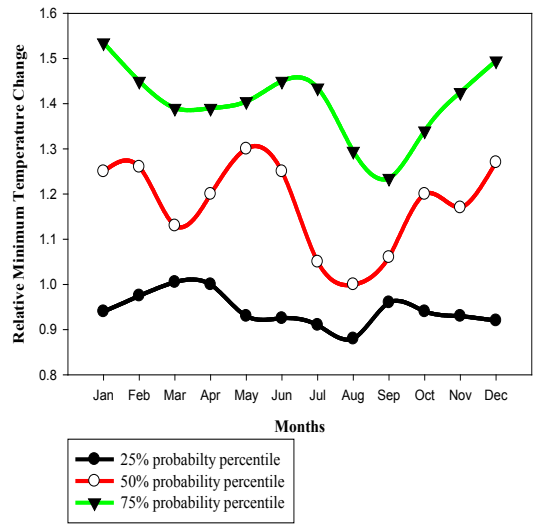

SRB1-2090s

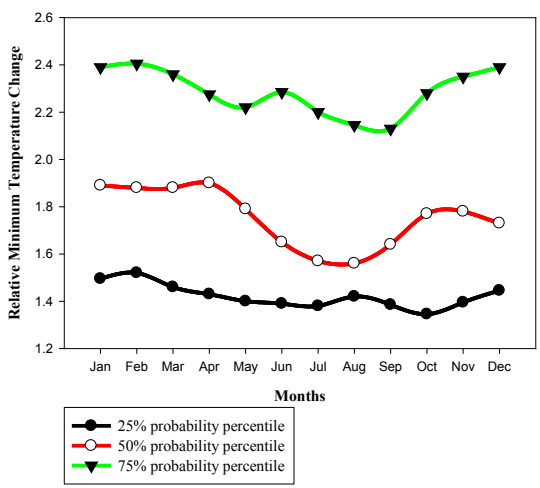

Figure 14. Estimated future changes in minimum temperature at three probability percentiles.

\section{Conclusion}

The study result indicates that LARS-WG 5.5 model is more ambiguous to simulate future mean rainfall than generating maximum and minimum temperature whereby weight difference among GCMs is 0.83 for rainfall and 0.09 for temperatures. The results of this study also indicate that mean annual rainfall changes of the area range from $-2.3 \%$ to $7 \%, 0.375 \%$ to $15.83 \%$ and $2.625 \%$ to 
SRA1B-2020s

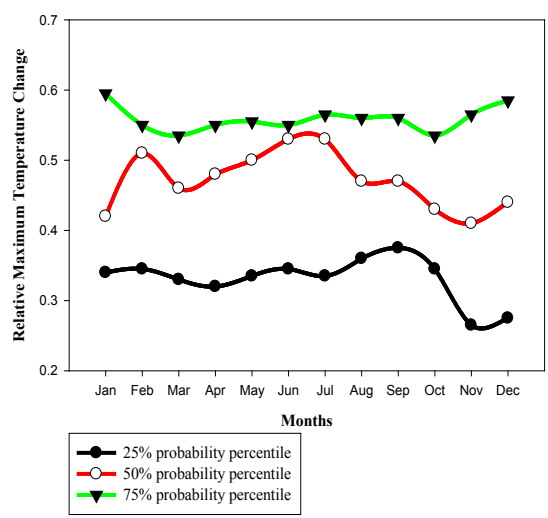

SRB1-2055s

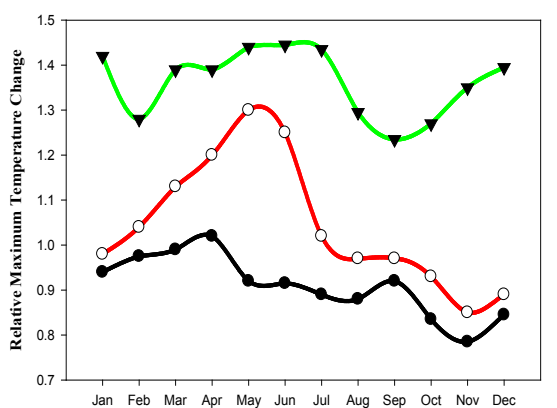

Months $\rightarrow-25 \%$ probability percentile
$\longrightarrow-50 \%$ probability percentile
$\longrightarrow-75 \%$ probability percentile

SRA1B-2090s

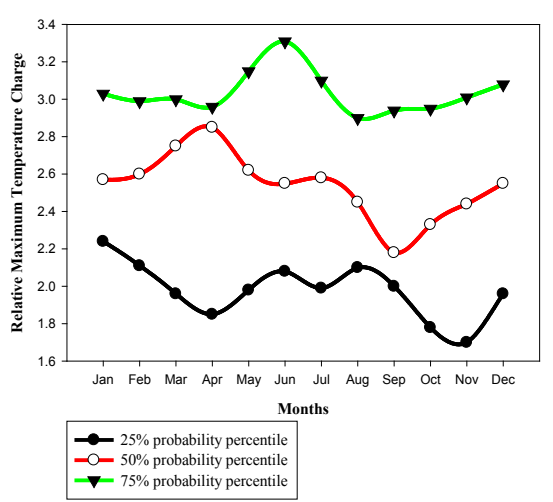

SRB1-2020s

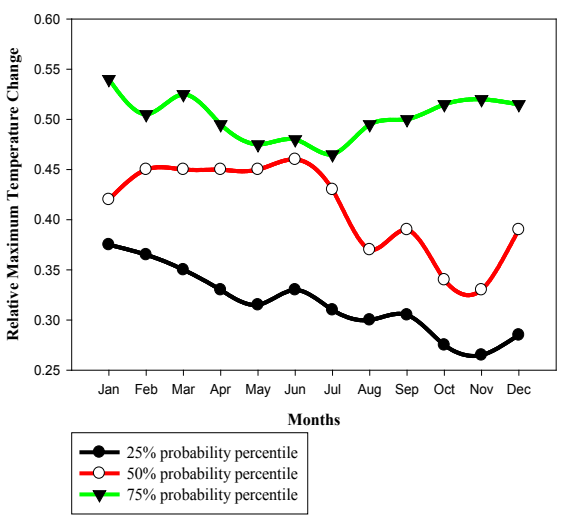

SRA1B-2055s

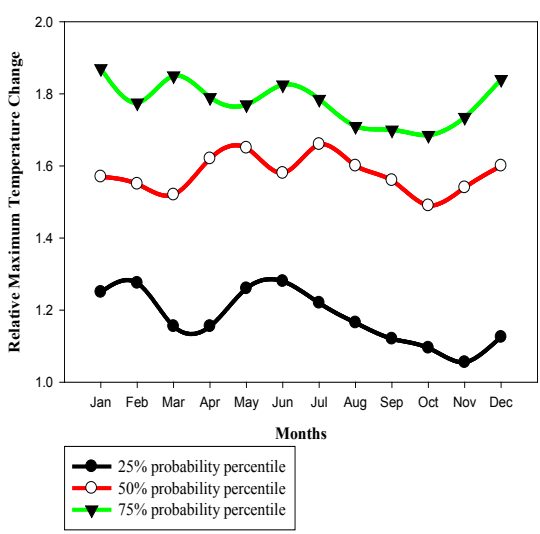

SRB1-2090s

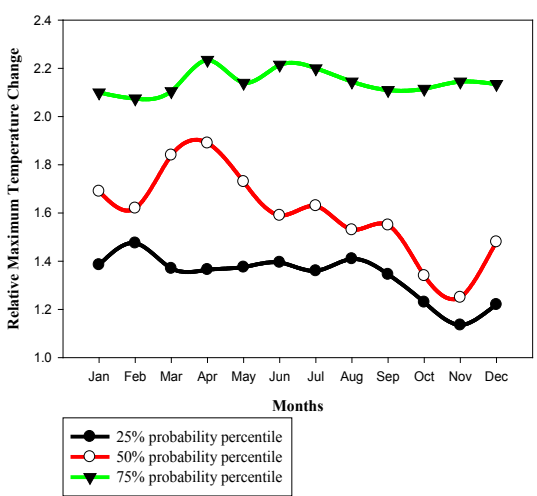

Figure 15. Estimated future changes in maximum temperature at three probability percentiles.

$31.1 \%$ in 2020s, 2055s and 2090s respectively. However, mean monthly rainfall patterns depicted both increase and decrease behavior in different months and time periods; indicating relatively rainfall decrease in summer ("Kiremt") and rainfall increase in winter ("Bega") for all three time periods and three probability percentiles. Ironically an overall increase in mean monthly temperature in all three time periods was observed. Average minimum temperature changes' range 
for $2020 \mathrm{~s}, 2055 \mathrm{~s}$ and $2090 \mathrm{~s}$ is $0.34^{\circ} \mathrm{C}$ to $0.58^{\circ} \mathrm{C}, 0.94^{\circ} \mathrm{C}$ to $1.8^{\circ} \mathrm{C}$ and $1.42^{\circ} \mathrm{C}$ to $3.2^{\circ} \mathrm{C}$ respectively. Similarly, changes in maximum temperature for the same time periods are $0.32^{\circ} \mathrm{C}$ to $0.56^{\circ} \mathrm{C}, 0.91^{\circ} \mathrm{C}$ to $1.8^{\circ} \mathrm{C}$ and $1.34^{\circ} \mathrm{C}$ to $3.04^{\circ} \mathrm{C}$ respectively. An overall temperature change for three time periods ranges from $0.32^{\circ} \mathrm{C}$ to $0.58^{\circ} \mathrm{C}, 0.91^{\circ} \mathrm{C}$ to $1.8^{\circ} \mathrm{C}$ and $1.34^{\circ} \mathrm{C}$ to $3.2^{\circ} \mathrm{C}$ in $2020 \mathrm{~s}, 2055 \mathrm{~s}$ and $2090 \mathrm{~s} \mathrm{respec}$ tively. Generated temperature change in coming time periods results indicates nearest result as compared with the 2007 report of the Intergovernmental Panel on Climate Change (IPCC) which indicates that in sub-Saharan Africa, temperatures will rise by over $3^{\circ} \mathrm{C}$ in 21 st century.

The same study released by national meteorological agency (NMA) of Ethiopia as explained above for rainfall using the IPCC mid-range (A1B) emission scenario, the mean annual temperature will increase in the range of $0.9^{\circ} \mathrm{C}$ $1.1^{\circ} \mathrm{C}$ by 2030 , in the range of $1.7^{\circ} \mathrm{C}-2.1^{\circ} \mathrm{C}$ by 2050 and in the range of $2.7^{\circ} \mathrm{C}-$ $3.4^{\circ} \mathrm{C}$ by 2080 over Ethiopia compared to the baseline 1961-1990 normal. Other sources of data have also substantiated the variability of climate and its trends in a somewhat similar way. Historical climate analysis for Ethiopia indicates that mean annual temperature has increased by $1.3^{\circ} \mathrm{C}$ between 1960 and 2006, an average rate of $0.28^{\circ} \mathrm{C}$ per decade.

\section{Conflicts of Interest}

The authors declare no conflicts of interest regarding the publication of this paper.

\section{References}

[1] IPCC (2007) Climate Change: Impacts, Adaptation and Vulnerability, Contribution of Working Group II to the Fourth Assessment. Report of the Intergovernmental Panel on Climate Change, Cambridge University Press, Cambridge.

[2] Cai, X., Wang, D. and Lauren, R. (2009) Impact of Climate Change on Crop Yield: A Case Study of Rainfed Corn in Central Illinois. Journal of Applied Meteorology and Climatology, 48, 1868-1881. https://doi.org/10.1175/2009JAMC1880.1

[3] Chen, H., Guo, J., Zhang, C. and Xu, C. (2013) Prediction of Temperature and Precipitation in Sudan and South Sudan by Using LARS-WG in Future. Theoretical and Applied Climatolology, 113, 363-375. https://doi.org/10.1007/s00704-012-0793-9

[4] Herrero, M., Ringler, C., van de Steeg, J., Thornton, P., Zhu, T., Bryan, E., Omolo, A., Koo, J. and Notenbaert, A. (2010) Climate Variability and Climate Change and Their Impacts on Kenya's Agricultural Sector. ILRI, Nairobi.

[5] Gebreegziabher, Z., Stage, J., Mekonnen, A. and Alemu, A. (2011) Climate Change and Ethiopian Economy. A Computable General Equilibrium Analysis. 11-09.

[6] Swarup, A., Dankelman, I., Ahluwalia, K. and Hawrylyshyn, K. (2011) Weathering the Storm: Adolescent Girls and Climate Change. Plan. http://www.plan-uk.org/resources/documents/35316

[7] You, G.J.Y. and Ringler, C. (2010) Hydro-Economic Modeling of Climate Change Impacts in Ethiopia. IFPRI Discussion Paper 00960

[8] World Bank (2010) Economics of Adaptation to Climate Change: Ethiopia. 
http://www-wds.worldbank.org/external/default/WDSContentServer/WDSP/IB/201 2/05/22/000425970_20120522100235/Rendered/PDF/686500ESW0P1130UBLIC00E ACC0Ethiopia.pdf

[9] Hassan, Z.B. (2012) Climate Change Impact on Precipitation and Stream Flow in a Humid Tropical Watershed.

[10] IPCC (2001) Impacts, Adaptation and Vulnerability, Contribution of Working Group II to the Third Assessment Report of the Intergovernmental Panel on Climate Change. Cambridge University Press, Cambridge.

[11] Smith, J.B. and Hulme, M. (1998) Climate Change Scenarios. In: Feenstra, J., Burton, I., Smith, J.B. and Tol, R.S.J., Eds., Handbook on Methods of Climate Change Impacts Assessment and Adaptation Strategies, Version 2.0, Vrije Universiteit, United Nations Environment Programme and Institute for Environmental Studies, Amsterdam, 3-40.

[12] https://en.actualitix.com/country/eth/ethiopia-co2-emissions-per-capita.php

[13] WRI (2017). http://cait2.wri.org

[14] IPCC (2001) Climate Change 2001: Impacts, Adaptation, and Vulnerability. Contribution of Working Group II to the Third Assessment Report of the Intergovernmental Panel on Climate Change, Cambridge University Press, Cambridge, 1032 p.

[15] Nakicenovic, N. and Swart, R. (2000) Emissions Scenarios. Special Report of the Intergovernmental Panel on Climate Change. Cambridge University Press, Cambridge.

[16] SNNPRS-RSA (2006) Southern Nations, Nationalities and People's Regional State-Regional Statistical Abstract, 2004/5. Bureau of Finance and Economic Development Division of Statistics and Population, Awasa.

[17] Houghton, J.T. and Ding (2000) Climate Change 2001: The Scientific Basis: Contribution of Working Group I to the Third Assessment Report of the Intergovernmental Panel on Climate Change. Cambridge University Press, Cambridge.

[18] Carter, T.R., Parry, M.L., Harasawa, H. and Nishioka, S. (1994) IPCC Technical Guidelines for Assessing Climate Change Impacts and Adaptations. University College/Centre for Global Environmental Research, London, Tsukuba.

[19] Mohammed, Y. (2009) Climate Change Impact Assessment on Soil Water Availability and Crop Yield in Anjeni Watershed Blue Nile Basin. Master Thesis, Arba Minch University, Arba Minch.

[20] Racsko, P., Szeidl, L. and Semenov, M.A. (1991) A serial Approach to Local Stochastic Weather Models. Ecological Modelling, 57, 27-41.

https://doi.org/10.1016/0304-3800(91)90053-4

[21] Semenov, M.A. and Barrow, E.M. (2002) LARS-WG: A Stochastic Weather Generator for Use in Climate Impact Studies (Version 3.0). User Manual.

[22] Semenov, M.A. and Stratonovitch, P. (2010) The Use of Multi-Model Ensembles from Global Climate Models for Impact Assessments of Climate Change. Climate Research, 41, 1-14. https://doi.org/10.3354/cr00836

[23] Gohari, A., Eslamian, S., Abedi-Koupaei, J., Bavani, A.M., Wang, D. and Madani, K. (2013) Climate Change Impacts on Crop Production in Iran's Zayandeh-Rud River Basin. Science of the Total Environment, 442, 405-419. https://doi.org/10.1016/j.scitotenv.2012.10.029

[24] Racsko, P., Szeidl, L. and Semenov, M.A. (1991) A Serial Approach to Local Stochastic Weather Models. Ecological Modelling, 57, 27-41.

https://doi.org/10.1016/0304-3800(91)90053-4 
[25] Massah Bavani, A.R. and Morid, S. (2005) The Impacts of Climate Change on Water Resources and Agricultural Production. Water Resources Research, 1, 40-47.

[26] Ines, A.V.M. and Hansen, J.W. (2006) Bias Correction of Daily GCM Rainfall for Crop Simulation Studies. Agricultural and Forest Meteorology, 138, 44-53. https://doi.org/10.1016/j.agrformet.2006.03.009

[27] Block, P.J., Souza Filho, F.A., Sun, L. and Kwon, H.H. (2009) A Stream Flow Forecasting Framework Using Multiple Climate and Hydrological Models. Journal of the American Water Resources Association, 45, 828-843. https://doi.org/10.1111/j.1752-1688.2009.00327.x

[28] Piani, C., Haerter, J.O. and Coppola, E. (2010) Statistical Bias Correction for Daily Precipitation in Regional Climate Models over Europe. Theoretical and Applied Climatology, 99, 187-192. https://doi.org/10.1007/s00704-009-0134-9

[29] Pindyck, R.S. (2012) Uncertain Outcomes and Climate Change Policy. Journal of Environmental Economics and Management, 63, 289-303. https://doi.org/10.1016/j.jeem.2011.12.001

[30] Teutschbein, C. and Seibert, J. (2012) Bias Correction of Regional Climate Model Simulations for Hydrological Climate-Change Impact Studies: Review and Evaluation of Different Methods. Journal of Hydrology, 456-457, 12-29. https://doi.org/10.1016/j.jhydrol.2012.05.052

[31] McSweeney, C., New, M. and Lizcano, G. (2010) UNDP Climate Change Country Profiles of Ethiopia Reports. https://doi.org/10.1175/2009BAMS2826.1

[32] F.D.R.E. (2011) Ethiopia's Climate-Resilient Green Economy: Green Economy Strategy. Federal Democratic Republic of Ethiopia, Addis Ababa. 


\section{Appendix}
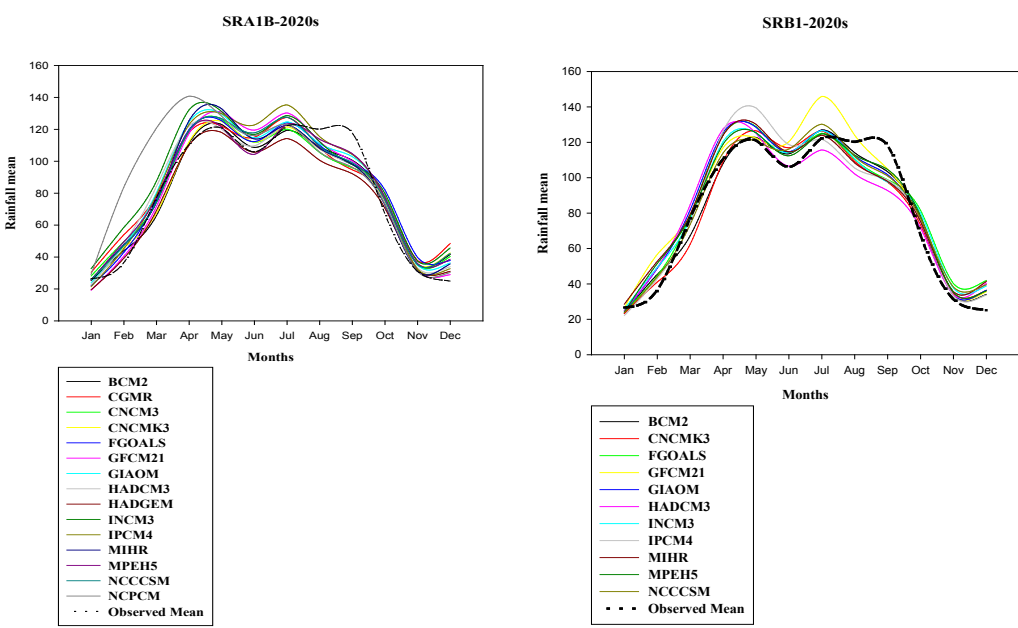

SRA1B-2055s

SRB1-2055s
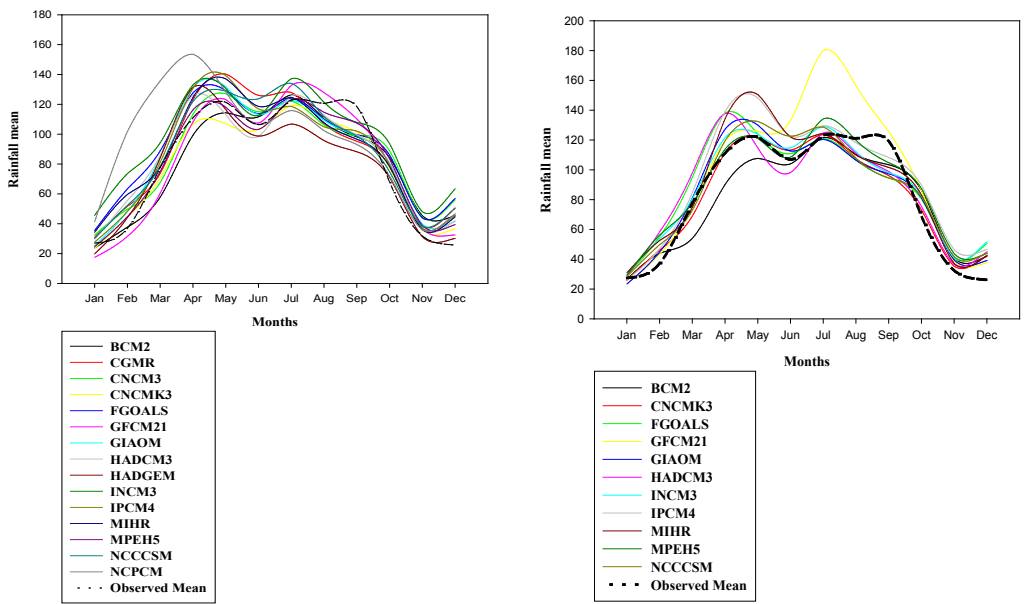

SRA1B-2090

SRB1-2090s
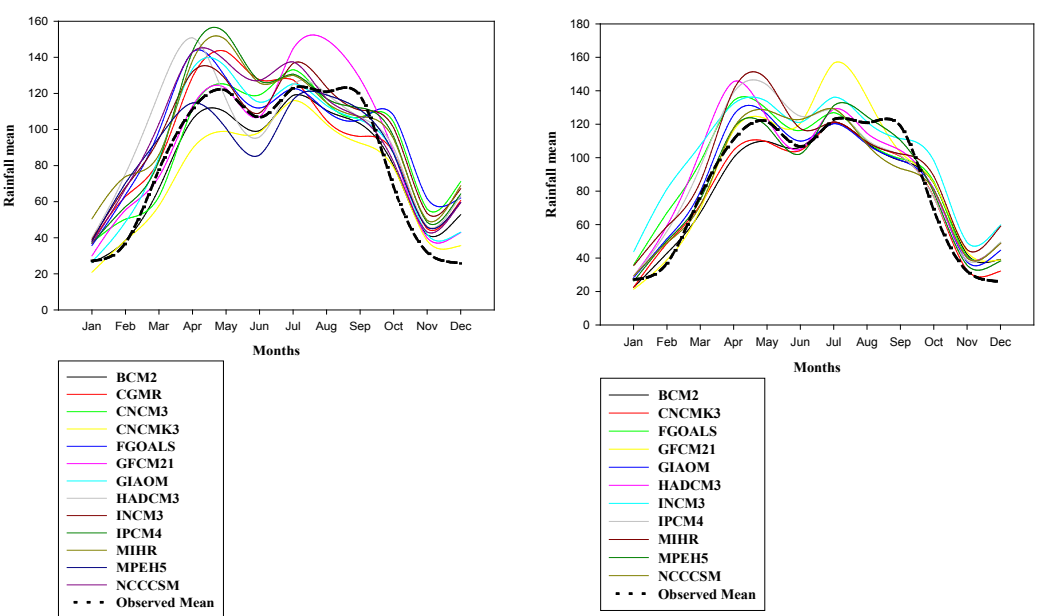

Months

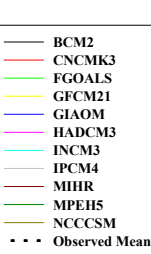

Figure A1. Monthly 15 GCMs model output of Simulated Versus Observed Rainfall mean under two emission scenarios and three time periods. The solid lines show mean of each 15 GCMs output and short dash black line is observed historical mean. 
SRA1B-2020s

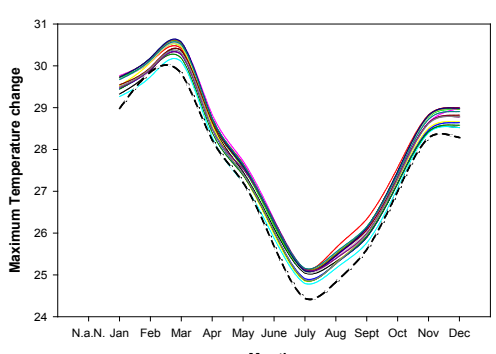

Months

\begin{tabular}{|c|}
\hline $\begin{array}{c}\text { BCM2 } \\
\text { CGMR } \\
\text { CNCM3 } \\
\text { CNCMK3 } \\
\text { CNCOALS } \\
\text { FGCM21 } \\
\text { GFCMOM } \\
\text { GIAOOM } \\
\text { HADCM3 } \\
\text { HADGEM } \\
\text { INCM3 } \\
\text { IPCM4 } \\
\text { MIHR } \\
\text { MIEH5 } \\
\text { NCCCSM } \\
\\
\text { NCPCM } \\
\text { Observed Mean }\end{array}$ \\
\hline
\end{tabular}

SRA1B-2055
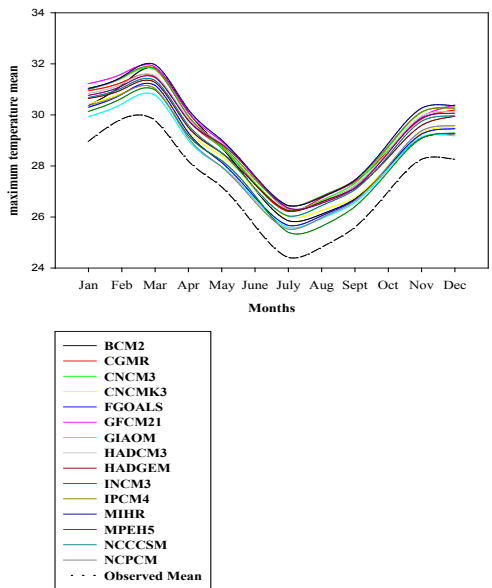

SRA1B-2090
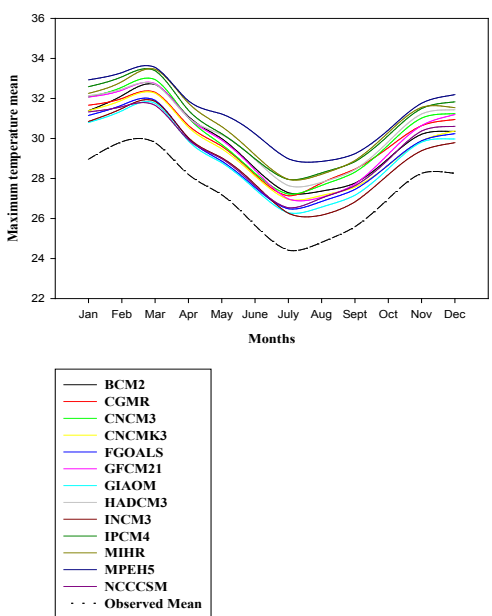

SRB1-2020s

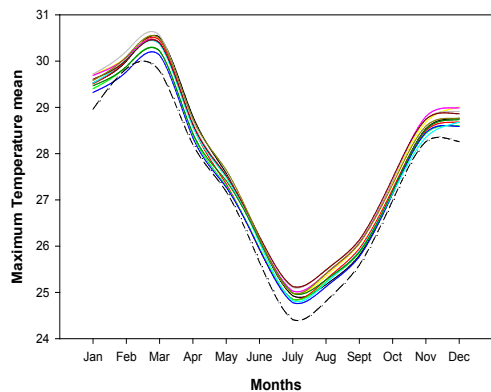

$$
\begin{array}{|c|}
\hline \text { BCM2 } \\
\hline \text { CNCMK3 } \\
\hline \text { FGOALS } \\
\text { GFCM21 } \\
\text { GIAOM } \\
\text { HADCM3 } \\
\hline \text { INCM3 } \\
\text { IPCM4 } \\
\text { IIHR } \\
\text { M MPEH5 } \\
\hline \text { NCCCSM } \\
\text { Observed Mean } \\
\hline
\end{array}
$$

SRB1-2055s

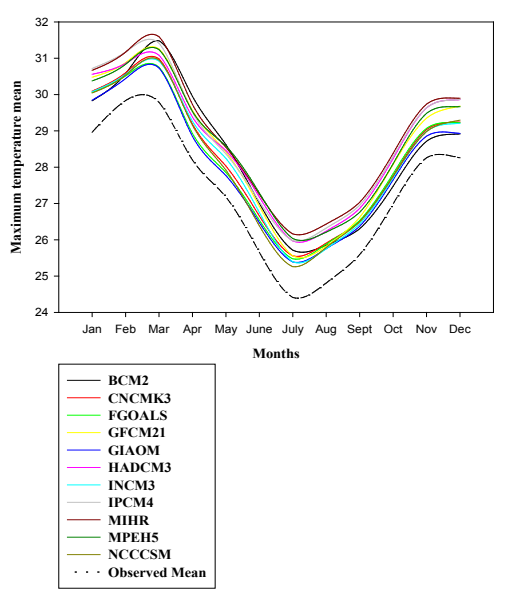

SRB1-2090s

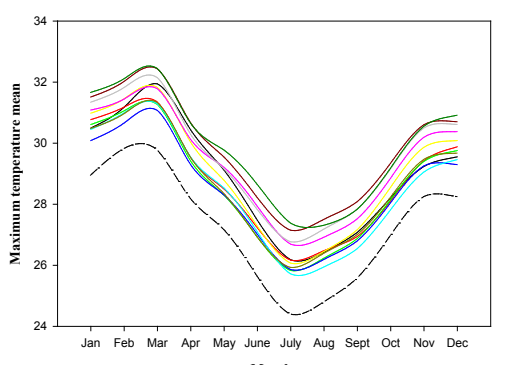

$$
\begin{array}{|l|}
\hline \text { BCM2 } \\
\hline \text { CNCMK3 } \\
\hline \text { FGOAS } \\
\text { GFCM21 } \\
\text { GIAOM } \\
\hline \text { HADCM3 } \\
\hline \text { INCM3 } \\
\text { IPCM4 } \\
\text { MIHR } \\
\hline \text { MPEH5 } \\
\hline \text { NCCCSM } \\
\text { Observed Mean } \\
\hline
\end{array}
$$

Figure A2. Monthly 15 GCMs model output of Simulated Versus Observed maximum temperature under two emission scenarios and three time periods. The solid lines show mean of each 15 GCMs output and short dash black line is observed historical mean. 
SRA1B-2020s

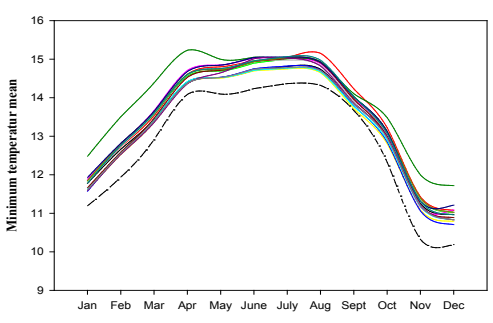
\begin{tabular}{|l|l|}
\hline BCM2 \\
\hline CGMR \\
CNCM3 \\
CNCMMK \\
FGOALS \\
GFCM21 \\
\hline GAOM \\
\hline HADCM3 \\
\hline HADGM \\
\hline INCM3 \\
IPCM4 \\
\hline MIRR \\
\hline MPES \\
\hline NCCSM \\
\hline NCPCM \\
Observed Mean \\
\hline
\end{tabular}

SRA1B-2055s

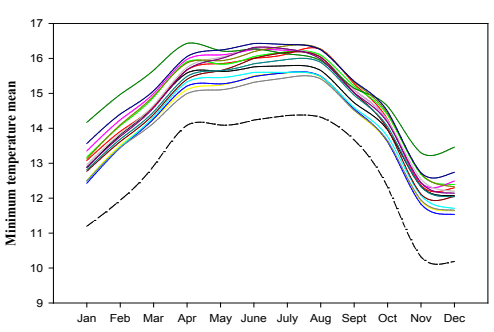

Month

\begin{tabular}{|l|l|}
\hline BCM2 \\
\hline CGMR \\
CNCM3 \\
CNCMK3 \\
CGOALS \\
\hline GFM21 \\
\hline GLAOM \\
\hline HADCM3 \\
\hline HADGEM \\
\hline INCM3 \\
IPCM4 \\
\hline MIIR \\
\hline MPEH5 \\
\hline NCCSM \\
NCPCM \\
Observed Mean \\
\hline
\end{tabular}

SRA1B-2090

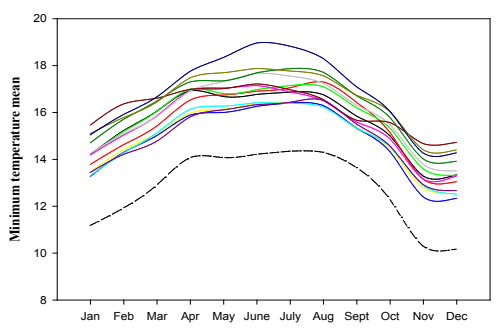

Months
SRB1-2020s

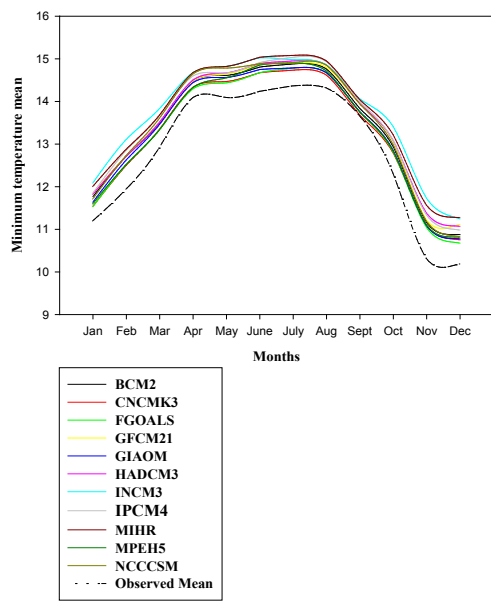

SRB1-2055s

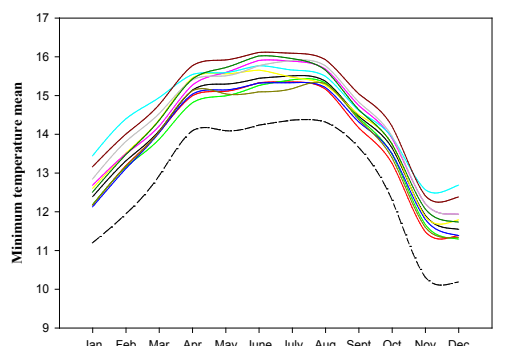

Months

\begin{tabular}{|l|}
\hline - BCM22 \\
\hline CNCMK3 \\
FGOALS \\
\hline GFCM21 \\
GIAOM \\
- HADCM3 \\
\hline INCM3 \\
\hline IPCM4 \\
IIHR \\
\hline MPEH5 \\
\hline NCCCSM \\
Observed Mean \\
\hline
\end{tabular}

SRB1-2090s

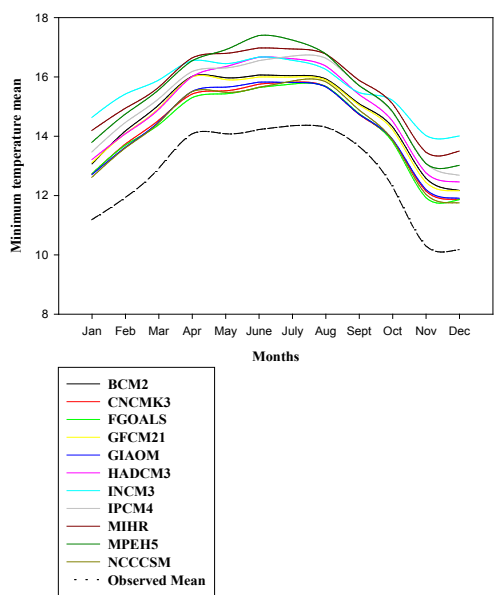

Figure A3. Monthly 15 GCMs model output of Simulated Versus Observed minimum temperature under two emission scenarios and three time periods. The solid lines show mean of each 15 GCMs output and short dash black line is observed historical mean. 